CAROLINE CRISTINA BORGES

Efeito de diferentes comprimentos de onda do laser diodo na descontaminação de dentina radicular infectada com Enterococcus Faecalis 

CAROLINE CRISTINA BORGES

\title{
Efeito de diferentes comprimentos de onda do laser diodo na descontaminação de dentina radicular infectada com Enterococcus Faecalis
}

\author{
Dissertação apresentada à Faculdade de \\ Odontologia de Ribeirão Preto da Universidade de \\ São Paulo para obtenção do Título de Mestre em \\ Ciências junto ao Programa de Odontologia \\ Restauradora com Área de Concentração em \\ Endodontia.
}

Orientador: Prof. Dr. Jesus Djalma Pécora

Versão corrigida. A versão original encontra-se disponível tanto na Biblioteca da Unidade que aloja o Programa, quanto na Biblioteca Digital de Teses e Dissertações da USP (BDTD).

Ribeirão Preto 
AUTORIZO A REPRODUÇÃO E DIVULGAÇÃO TOTAL OU PARCIAL DESTE TRABALHO, POR QUALQUER MEIO CONVENCIONAL OU ELETRÔNICO, PARA FINS DE ESTUDO E PESQUISA, DESDE QUE CITADA A FONTE.

FICHA CATALOGRÁFICA

Elaborada pela Biblioteca Central do Campus USP - Ribeirão Preto

Borges, Caroline Cristina

Efeito de diferentes comprimentos de onda do laser diodo na descontaminação de dentina radicular infectada com Enterococcus Faecalis. Ribeirão Preto, 2016.

90p: il.; $30 \mathrm{~cm}$

Dissertação apresentada à Faculdade de Odontologia de Ribeirão Preto da Universidade de São Paulo como parte dos requisitos para obtenção do Título de Mestre em Ciências - Área de Concentração em Endodontia.

Orientador: Pécora, Jesus Djalma

1. Enterococcus faecalis. 2. Laser diodo. 3. Clorexidina. 4. Hipoclorito de sódio. 
Borges, C. C. Efeito de diferentes comprimentos de onda do laser diodo na descontaminação de dentina radicular infectada com Enterococcus Faecalis. 2016, 89p. Dissertação (mestrado) - Faculdade de Odontologia de Ribeirão Preto, Universidade de São Paulo, Ribeirão Preto, 2016.

Aprovado em:

\section{Banca Examinadora}

Prof. Dr. Jesus Djalma Pécora (Orientador)

Instituição: Faculdade de Odontologia de Ribeirão Preto/USP

Julgamento:

Assinatura:

$\operatorname{Prof}(a) . \operatorname{Dr}(a)$.

Instituição:

Julgamento:

Assinatura:

Prof(a). Dr(a).

Instituição:

Julgamento:

Assinatura: 


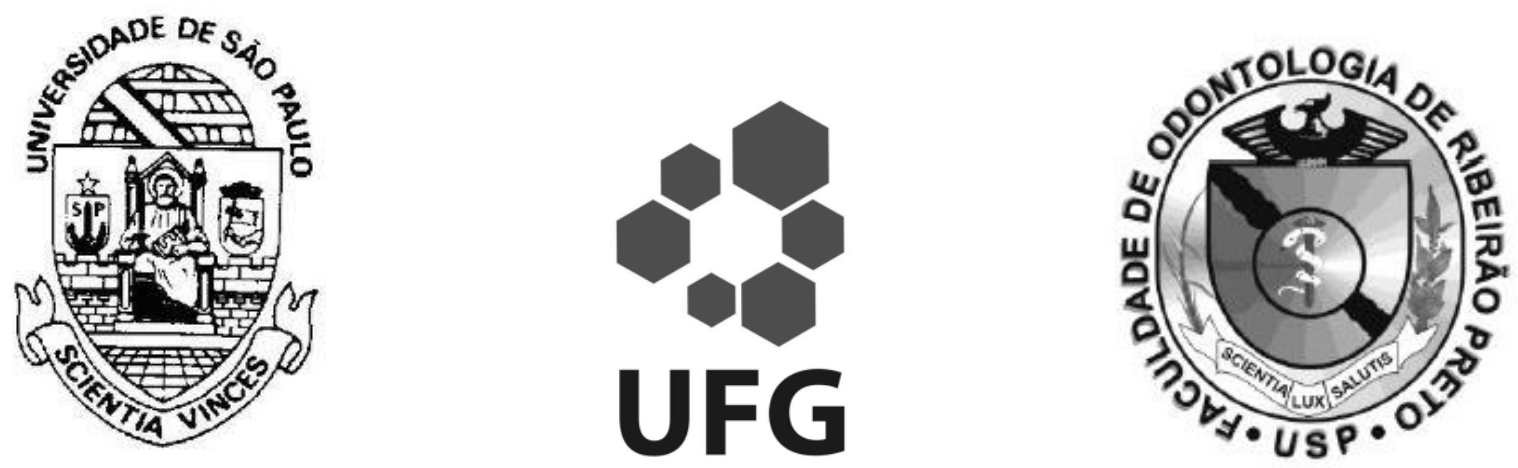

Este trabalho de pesquisa foi realizado nas seguintes instituições: Laboratório de Pesquisa em Endodontia do Departamento de Odontologia Restauradora da Faculdade de Odontologia de Ribeirão Preto da Universidade de São Paulo e Faculdade de Odontologia da Universidade Federal de Goiás, com auxílio do CNPq. 



Agradeço primeiramente à Deus, por me conceder saúde e condições para superar os desafios de cada dia, guiando e iluminando meu caminho.

Aos meus pais, Carlos César Borges e Maria de Fátima Borges, que tornaram possível todo meu aprendizado e por contribuírem na minha formação sendo exemplos de dedicação, honestidade e caráter.

Ao meu irmão, Carlos César Borges Filho, melhor amigo, que mesmo distante, se mostrou presente me apoiando e fortalecendo nos momentos difíceis.

Ao meu namorado, Victor Jacometti, amigo e companheiro de todos os momentos. Obrigada por acreditar em mim, pela paciência, disposição em me ajudar e estar sempre do meu lado.

À minha querida avó, Irene Batista Borges, que foi uma grande mulher e meu maior exemplo, por demonstrar amor na simplicidade do seu trabalho habitual e nos pequenos detalhes de cada dia. Obrigada pela admiração que depositou em mim e por me fazer sentir tão especial. Amo demais, flor do dia. 

Agradecimentos 

Ao meu orientador, Prof. Dr. Jesus Djalma Pécora, exemplo de dedicação e perseverança, pelos ensinamentos e orientações durante o desenvolvimento deste projeto.

Ao Prof. Dr. Carlos Estrela, por todo incentivo e direcionamento durante o desenvolvimento deste projeto, por todas as orientações, por exercer papel fundamental na minha formação, desde minha graduação e contribuído para minha escolha por esta especialidade.

Ao Prof. Dr. Manoel Damião de Sousa Neto, pela oportunidade da realização do curso de mestrado, pelos conhecimentos compartilhados que exerceram um papel fundamental na minha formação científica.

À Profa. Dra. Cyntia Rodrigues De Araújo Estrela por todo direcionamento e conhecimento passado durante o trabalho experimental. Agradeço imensamente a grande atenção, disponibilidade e dedicação.

À Profa. Dra. Regina Guenka Palma Dibb, exemplo de trabalho, sempre disposta a passar seus conhecimentos. Muito obrigada pela abertura de realizar discussões, tirar dúvidas, pela agradável convivência, e pelo constante aprendizado.

Aos Docentes do Departamento de Odontologia Restauradora da Faculdade de Odontologia de Ribeirão Preto - Universidade de São Paulo, pelos conhecimentos transmitidos e acolhimento.

Aos alunos da pós-graduação do Departamento de Odontologia Restauradora da Faculdade de Odontologia de Ribeirão Preto da Universidade de São Paulo, Luis Eduardo Souza Flamini, Igor Petean, Larissa Ernesto, Graziela Bianchi Leoni, Vanessa Lessa, Bruno Crozeta, Amanda Buosi Biagi, Isadora Soares pela 
convivência agradável, estímulo, ajuda e troca de experiências, pela amizade, carinho, ajuda e atenção durante esses dois anos.

À Fabiane Carneiro Lopes, ao Jardel Chaves Mazzi e ao Rodrigo Pereira Dantas, pela grande ajuda, disponibilidade e pelos ensinamentos passados durante esse trabalho.

Aos meus queridos amigos, Lívia Campi Bueno, Paulo André, Flávia Cássia Cabral Rodrigues, Fabiana Curylofo e Bruno Matos, que conviveram comigo nessa fase e demonstraram ser grandes amigos nessa adaptação de morar em outra cidade e por fazer parte da minha vida e torcer por meu sucesso.

Aos funcionários Reginaldo Santana e Carlos Feitosa dos Santos, pela ajuda e disponibilidade para a execução deste trabalho, pelo convívio diário sempre alegre.

Às funcionárias, Luiza Pitol, Rosângela Anglini, Maria Amália Viesti de Oliveira, Maria Isabel C. Francisco Miguel e Dra. Débora Fernandes Costa, técnica do laboratório de Gerenciamento de Resíduos Químicos/FORP- USP pela amizade e dedicação.

Ao Conselho Nacional de Desenvolvimento Científico e Tecnológico (CNPq), pela bolsa concedida para o meu desenvolvimento e desse projeto.

À Faculdade de Odontologia de Ribeirão Preto da Universidade de São Paulo e ao Departamento de Odontologia Restauradora, pela oportunidade da realização do curso de mestrado, permitindo meu crescimento profissional e pessoal. 
"A mente que se abre a uma nova ideia, jamais voltará a seu tamanho original. '

(Albert Eistein) 

Resumo 

Borges, C. C. Efeito de diferentes comprimentos de onda do laser diodo na descontaminação de dentina radicular infectada com Enterococcus Faecalis. 2016, 90p. Dissertação (mestrado) - Faculdade de Odontologia de Ribeirão Preto, Universidade de São Paulo, Ribeirão Preto, 2016.

\section{RESUMO}

O objetivo do presente estudo foi avaliar o efeito antibacteriano do laser diodo com diferentes comprimentos de onda em blocos de dentina infectados com Enterococcus faecalis, por meio de análise microbiológica com espectrofotometria e alterações ultraestruturais por meio de microscópio eletrônico de varredura. Treze dentes unirradiculares foram seccionados de forma a obter 100 blocos de dentina intrarradicular. Inicialmente, os blocos foram imersos por 5 minutos em EDTA 17\% e em seguida lavados por 5 minutos com água destilada, e então autoclavados por 30 minutos a $120^{\circ} \mathrm{C}$. As amostras de dentina foram inoculadas com $1 \mathrm{~mL}$ de suspensão de $E$. faecalis em $5 \mathrm{~mL}$ de $\mathrm{BHI}$ (Brain Heart Infusion) e incubadas a $37^{\circ} \mathrm{C}$ por cinco dias. Após a contaminação, os espécimes foram distribuídos em dez grupos $(n=10)$ de acordo com tratamento de superfície: Gl $-5 \mathrm{~mL} \mathrm{NaOCl} \mathrm{2,5 \% ,} \mathrm{GII} \mathrm{-} 5 \mathrm{~mL} \mathrm{NaOCl}$ 2,5\% + diodo 808nm, GIII - $5 \mathrm{~mL} \mathrm{NaOCl} 2,5 \%$ + diodo 970nm, GIV - diodo 808nm, GV - diodo 970nm, GVI - CHX 2\%, GVII - CHX 2\% + diodo 808nm, GVIII - CHX 2\% + diodo $970 \mathrm{~nm}$, GIX - controle positivo e GX - controle negativo. O crescimento bacteriano foi analisado pela turbidez e densidade óptica do meio de cultura por espectrofotometria $(\mathrm{nm})$. Em seguida, os espécimes foram preparados para análise das alterações ultraestruturais da superfície dentinária em MEV. Os dados foram submetidos ao teste ANOVA um fator e evidenciaram que o Gl $(77,5 \pm 12,1)$, Gll $(72,5 \pm 12,2)$, GIII $(68,7 \pm 8,7)$, GV $(68,3 \pm 8,7)$, GVI $(62,0 \pm 5,5)$ e GVII $(67,5 \pm 3,3)$ foram semelhantes entre si e diferente estatisticamente dos grupos GIV $(58,8 \pm$ $25,0)$, GVIII $(59,2 \pm 4,0)$ e grupos controles $(p<0,05)$. A análise em MEV evidenciou uma matriz orgânica amorfa e derretimento da dentina intertubular quando submetidos à irradiação do laser diodo $970 \mathrm{~nm}$, e erosão da dentina intertubular quando irradiada com laser $808 \mathrm{~nm}$, sendo que ao associar $\mathrm{NaOCl} 2,5 \%$ ao laser com diferentes comprimentos de onda, observou-se maior erosão intertubular. Conclui-se que todos os protocolos terapêuticos foram capazes de reduzir o contingente bacteriano dos blocos de dentina e ao associar o laser diodo e soluções não houve melhora significativa na redução do contingente bacteriano.

Palavras-chave: Enterococcus faecalis, laser diodo, clorexidina, hipoclorito de sódio. 

Abstract 

Borges, C. C. Effect of different diode laser wavelengths on root dentin decontamination infected with Enterococcus faecalis 2016, 90p. Dissertação (mestrado) - Faculdade de Odontologia de Ribeirão Preto, Universidade de São Paulo, Ribeirão Preto, 2016.

\begin{abstract}
The objective of this study was to evaluate the disinfection degree of dentin blocks contaminated by Enterococcus faecalis caused by different diode laser wavelengths through microbiological analysis with spectrophotometry and ultrastructural alterations by scanning electron microscope. Thirteen uniradicular teeth were sectioned into 100 dentin Intraradicular blocks. Initially, the blocks were immersed for 5 minutes in 17\% EDTA and then washed for 5 minutes with distilled water, and then esterilized for 30 minutes at $120^{\circ} \mathrm{C}$. The dentin samples were inoculated with $1 \mathrm{~mL}$ of E. faecalis suspension in $5 \mathrm{~mL} \mathrm{BHI}$ (Brain Heart Infusion) and incubated at $37^{\circ} \mathrm{C}$ for five days. After contamination, the specimens were distributed into ten groups $(\mathrm{n}=$ 10) according to surface treatment: Gl $-5 \mathrm{~mL} \mathrm{NaOCl} 2.5 \%$, Gll $-5 \mathrm{~mL} \mathrm{NaOCl} 2.5 \%+$ diode $808 \mathrm{~nm}$, Glll - $5 \mathrm{~mL} \mathrm{NaOCl} 2.5 \%$ + diode 970nm, GIV - diode 808nm, GV diode $970 \mathrm{~nm}, \mathrm{GVI}-\mathrm{CHX} 2 \%$, GVII - CHX 2\% + diode 808nm, GVIII - CHX $2 \%+$ diode $970 \mathrm{~nm}$, GIX - positive control and GX - Negative control. Bacterial growth was analyzed by turbidity and optical density of the culture medium by spectrophotometry $(\mathrm{nm})$. Afterwards, the specimens were processed for analysis of the ultrastructural changes of the dentin surface in SEM. The data was subject to the One-way ANOVA test and showed that GI $(77,5 \pm 12,1)$, Gll $(72,5 \pm 12,2)$, GIII $(68,7 \pm 8,7)$, GV $(68,3 \pm$ $8,7)$ and GVII $(67,5 \pm 3,3)$ were statistically similar and statistically different from GIV $(58,8 \pm 25,0)$, GVIII $(59,2 \pm 4,0)$ and control groups $(p<0.05)$. SEM analysis showed a modified organic matrix layer with an amorphous, intertubular dentin melting when dentin samples were irradiated with $970 \mathrm{~nm}$ diode laser, erosion of the intertubular dentin in blocks submitted to $808 \mathrm{~nm}$ diode laser, and a increased erosion of the intertubular dentin when associating $\mathrm{NaOCl} 2,5 \%$ to the laser with different wavelengths. All the therapeutic protocols were able to reduce the bacterial contingent in dentin blocks with the association of laser diode and solutions did not significantly improve the reduction of the bacterial contingent.
\end{abstract}

Key-words: Enterococcus faecalis, diode laser, clorexidine, sodium hipoclorite. 

Sumário 




\section{SUMÁRIO}

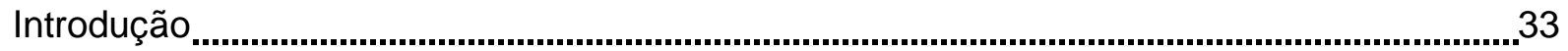

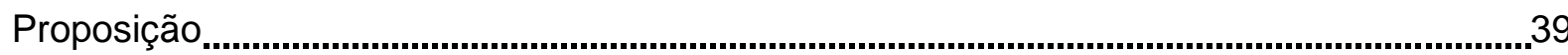

Material e Métodos

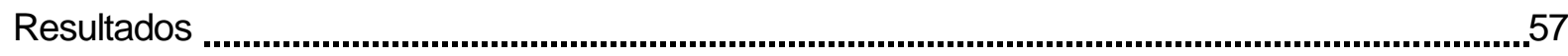

Discussão,

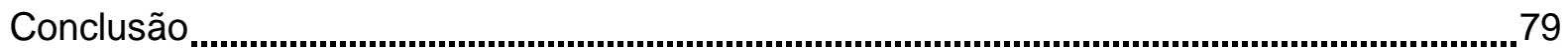

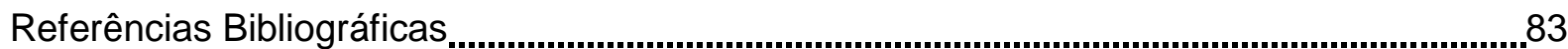




Introdução 

A desinfecção do sistema de canais radiculares tem como objetivo eliminar agentes irritantes como bactérias, seus produtos e restos de tecido pulpar, proporcionando um ambiente favorável ao reparo dos tecidos periapicais (Bazvand, Aminozarbian et al., 2014; Saha, Nair et al., 2015) por meio da ação conjunta de instrumentos endodônticos auxiliados pelas soluções irrigantes e medicação intracanal(Reddy, Latha et al., 2014; Afkhami, Pourhashemi et al., 2015; Kiran, Prakash et al., 2016; Vatkar, Hegde et al., 2016).

Entretanto, as variações da anatomia interna dos canais radiculares como achatamentos, presença de istmos, reentrâncias e ramificações podem interferir no sucesso da desinfecção dificultando a execução das técnicas de instrumentação e favorecendo a persistência de remanescentes teciduais e bactérias (Leoni, Versiani et al., 2014; Versiani, Ordinola-Zapata et al., 2016). Além disso, a dentina apresenta característica tubular com conformação cônica e diâmetro maior localizado próxima a luz do canal, o que permite a penetração de bactérias em áreas mais profundas da dentina (Ribeiro, Marchesan et al., 2010).

A profundidade de penetração bacteriana nos túbulos dentinários é de $500 \mu \mathrm{m}$ (Parmar, Hauman et al., 2011; Brittan, Sprague et al., 2016). A espécie bacteriana Enterococcus faecalis, especificamente, que apresenta alta prevalência em casos de periodontite apical persistente (Stuart, Schwartz et al., 2006), é conhecida por se estender à uma profundamente ainda maior, penetrando 800-1000 $\mu \mathrm{m}$ nos túbulos dentinários após 3 semanas de incubação (Haapasalo e Orstavik, 1987; Ran, Gu et al., 2015).

O hipoclorito de sódio é capaz de alcançar profundidades de penetração de até $300 \mu \mathrm{m}$ nos túbulos dentinários(Zou, Shen et al., 2010; Wong e Cheung, 2014). Assim como hipoclorito, a profundidade de penetração da clorexidina mesmo após a instrumentação é menor do que a capacidade de penetração microbiana (Kandaswamy, Venkateshbabu et al., 2010). Sendo assim, bactérias e endotoxinas 
podem permanecer nos túbulos dentinários, uma vez que o preparo biomecânico e as soluções irrigantes não são capazes de eliminar completamente as bactérias em regiões mais profundas dos túbulos dentinários (Wong e Cheung, 2014).

Atualmente, além das soluções irrigantes a radiação laser tem sido proposta para auxiliar a desinfecção dos canais radiculares(Zou, Shen et al., 2010; AlKaradaghi, Franzen et al., 2015; Muhammad, Rocca et al., 2015; Romeo, Palaia et al., 2015; Tosun, Culha et al., 2016). A radiação laser é um tipo de luz não-ionizada altamente concentrada que, em contato com o tecido, resulta em efeitos diversos, dependendo do comprimento de onda e das propriedades ópticas do tecido irradiado. Além disso, outros fatores podem interferir no efeito da irradiação, como por exemplo, os parâmetros de potência e frequência (Gulsoy, Dereli et al., 2006; Violich e Chandler, 2010; Afkhami, Pourhashemi et al., 2015).

Dentro desse contexto, o potencial de aplicação do laser no campo da Endodontia tem evoluído com objetivo de promover a desinfecção do sistema de canais radiculares (Hmud, Kahler et al., 2010; Asnaashari e Safavi, 2013; Gutknecht, Al-Karadaghi et al., 2016).

O laser diodo em diferentes comprimentos de onda (970nm e 808nm) foi desenvolvido para aplicação em Endodontia, apresentando fibras ópticas finas, com 200-320 $\mu \mathrm{m}$ de diâmetro, que permitem adaptação às dimensões reduzidas e curvaturas dos canais radiculares, possibilitando a descontaminação ao longo do conduto (Brugnera, Zanin et al., 2003), bem como a ação do laser no terço apical do canal radicular (Beer, Buchmair et al., 2012; Maenosono, Bim Junior et al., 2015; Lopes, Roperto et al., 2016).

Por possuir comprimento de onda próximo ao infravermelho, o laser diodo é capaz de atingir camadas mais profundas da dentina (Alfredo, Souza-Gabriel et al., 2009), agindo onde as soluções irrigantes são incapazes de atuar, reduzindo assim o número de microrganismos resistentes (Schoop, Kluger et al., 2006; Kanumuru e 
Subbaiah, 2014). Além disso, o laser diodo é capaz de aumentar a permeabilidade dentinária e remover a camada de smear na dentina intrarradicular (MARCHESAN et al., 2008; AL-KARADAGHI et al., 2015) sem alterar a estrutura química da mesma (LOPES et al., 2016).

O mecanismo de ação do laser diodo para diminuir o contingente bacteriano no interior do canal radicular está relacionado à conversão de energia radiante em energia térmica nos tecidos por um curto prazo de tempo (GEREK; ASCI; YAYLALI, 2010). Tanto o laser diodo com comprimento de onda de $808 \mathrm{~nm}$ como $970 \mathrm{~nm}$, promovem alterações à nível de parede celular bacteriana (MORRITZ, 1997; LÓPEZ-JIMÉNEZ et al., 2015).

A persistência de bactérias nos canais radiculares é um desafio para a Endodontia uma vez que o controle e eliminação dos microrganismos são necessários para que se alcance o sucesso do tratamento endodôntico (FERNANDES; DE ATAIDE, 2010). Visto que as soluções irrigantes possuem limitações quanto à profundidade de penetração nos túbulos dentinários (VALERA et al., 2016; PLADISAI et al., 2016) e que a erradicação de espécies bacterianas dos canais radiculares ainda não foi alcançada, novos estudos utilizando ferramentas auxiliares são necessários para garantir sucesso do tratamento endodôntico.

A proposta do presente estudo foi avaliar o efeito antibacteriano do laser diodo de diferentes comprimentos de onda $(808 \mathrm{~nm}$ e $970 \mathrm{~nm})$ e sua associação com soluções irrigantes (hipoclorito de sódio 2,5\% e clorexidina $2 \%$ ) na dentina radicular contaminada por um biofilme de cinco dias. 

$\boldsymbol{P}_{\text {roposição }}$ 

A proposta do presente estudo foi avaliar, o efeito antibacteriano do laser diodo de diferentes comprimentos de onda (808nm e 970nm) e sua associação com soluções irrigantes (hipoclorito de sódio 2,5\% e clorexidina 2\%) na dentina radicular contaminada. 

Materiale Métodos 



\section{Seleção e preparo das amostras}

O presente estudo foi realizado após aprovação do Comitê de Ética em Pesquisa da Faculdade de Odontologia de Goiás (FO/UFG) sob número CAAE 19811113.0.0000.5083.

Foram cedidos por pacientes maiores de 18 anos da Faculdade de Odontologia / Universidade Federal de Goiás, dentes anteriores superiores e pré-molares inferiores unirradiculares, com indicação de exodontia por motivo periodontal ou ortodôntico. Os dentes foram lavados em água corrente por 24 horas, e, em seguida, tiveram sua superfície externa limpa por meio de raspagem ultrassônica (Profi II Ceramic, Dabi Atlante Ltda., Ribeirão Preto, SP, Brasil).

Os dentes foram radiografados nos sentidos orto e mésio-radial com filme Ektaspeed EP (Kodak Brasileira Comércio e Indústria Ltda, São José dos Campos, SP, Brasil), tempo de exposição de 0,5 segundo e distância objeto-foco de $10 \mathrm{~cm}$. As radiografias foram avaliadas com auxílio de negatoscópio (Konex, Konex Ind. E Com. de Metais, Ltda, São Paulo, SP, Brasil) e de aparato visualizador magnificador (X-Produkter, Malmö, Suécia). Após exame macroscópico e radiográfico, 13 dentes foram selecionados obedecendo aos seguintes critérios de inclusão: dentes unirradiculares, com raízes completamente formadas, ausência de calcificação e reabsorções, sem achatamento e curvatura acentuada e ausência de tratamento endodôntico prévio (Figura 1A). Os dentes selecionados foram acondicionados em frascos contendo solução de timol $0,1 \%$ a $9^{\circ} \mathrm{C}$ por 48 horas até o momento de obtenção dos blocos.

Os dentes foram fixados em placas de acrílico com godiva de baixa fusão em bastão (DFL, Porto Alegre, RS, Brasil). Em seguida, foram acoplados a um dispositivo de fixação na máquina de corte (Labcut 1010, Erios, São Paulo, SP, Brasil) (Figura 1B e C), e seccionados perpendicularmente ao longo eixo da raiz de forma a obter dois slices de 2 
$\mathrm{mm}$ de espessura do terço cervical de cada um dos dentes, obtendo-se assim, 26 slices (Figura 1D).

Os terços médio e apical juntamente à parte coronária foram descartados, sendo apenas o slice cervical utilizado neste estudo. Cada slice cervical de dentina foi seccionado duas vezes. A primeira secção (Figura $1 \mathrm{E}-\mathrm{a}$ ), no plano sagital do slice dividindo o mesmo ao meio, e a segunda secção no plano frontal (Figura 1 E-b).

Os blocos foram ajustados com disco de polimento fino (3M ESPE Dental Products, St. Paul, MN, EUA) e suas medidas verificadas com auxílio de paquímetro digital (Mitutoyo, Suzano, SP, Brasil), de forma a obter as dimensões de $4 \mathrm{~mm}$ de altura, 4 $\mathrm{mm}$ de largura e $2 \mathrm{~mm}$ de espessura (Figura 1F), totalizando 104 blocos de dentina. Foram selecionados aleatoriamente 100 blocos para a realização deste estudo, sendo os outro 4 descartados.

Após o preparo, os blocos foram colocados em becker de $150 \mathrm{~mL}$ com ácido etilenodiaminotetracético (EDTA 17\%) (Fórmula e Ação, São Paulo, SP, Brasil) e mantidos sob agitação em agitador de tubos (Vortex, Modelo AP 56, Presidente Prudente, SP, Brasil) por 5 minutos. Posteriormente, o mesmo processo foi realizado, porém, utilizando água destilada. Os blocos foram mantidos hidratados em um becker de $150 \mathrm{~mL}$ por 24 horas em estufa. Em seguida, a água destilada do becker foi removida e uma nova água destilada foi colocada para que os blocos fossem mantidos hidratados durante a esterilização em autoclave vertical analógica (Idealclave, Stermax, Barueri, São Paulo, Brasil) por 30 minutos à $120^{\circ} \mathrm{C}$. Após a esterilização, os blocos foram incubados em $\mathrm{BHI}$ a $37^{\circ} \mathrm{C}$ por 48 horas para confirmar a ausência de bactérias por meio de análise visual. Os blocos foram deixados em solução salina esterilizada até o momento do uso (Figura 1G e H). 


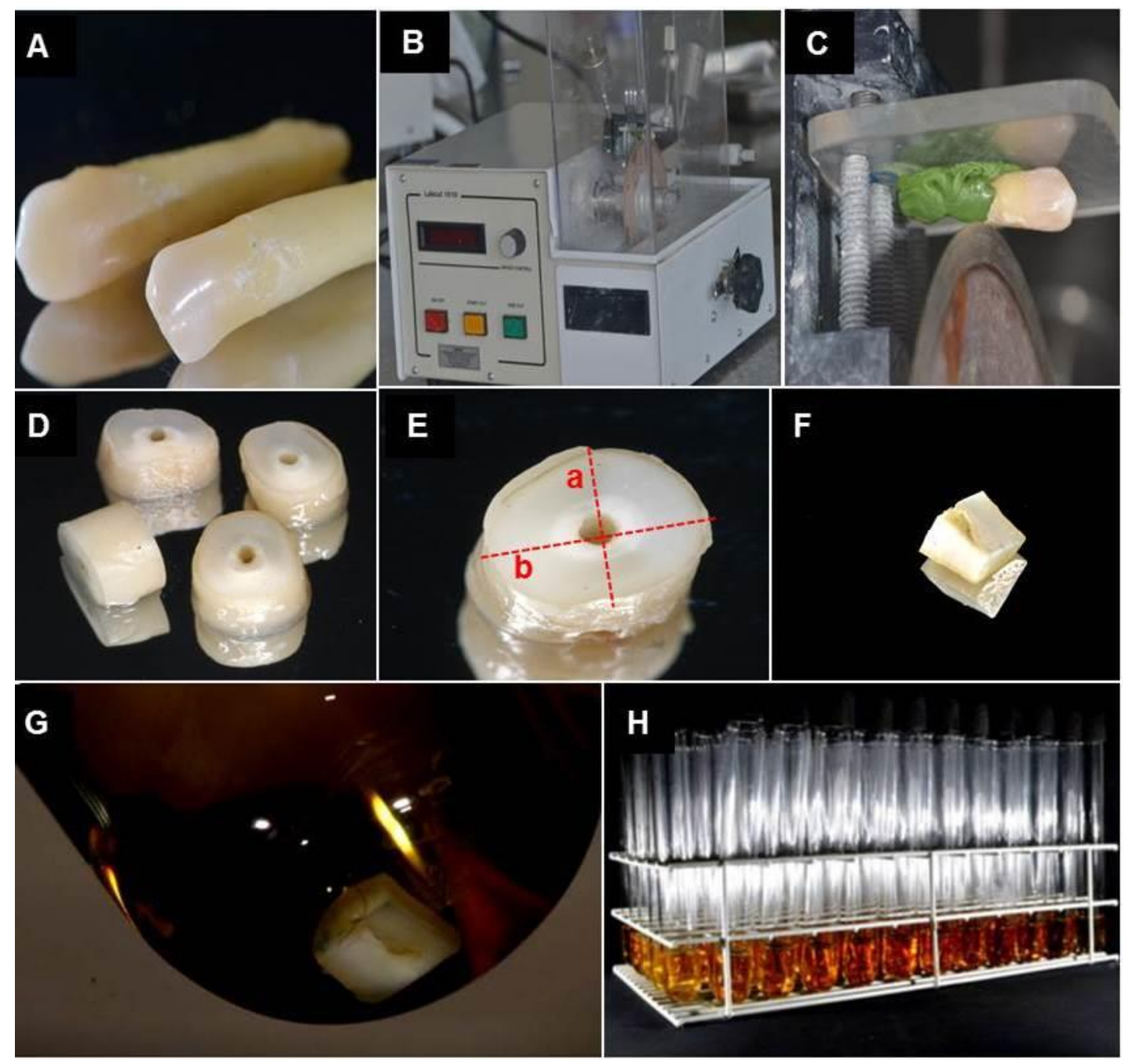

Figura 1. (A) Seleção dos dentes obedecendo os critérios de inclusão; (B) Máquina de corte; (C) Dentes acoplados ao dispositivo de fixação na máquina de corte; (D) Slices obtidos dos terços cervicais, (E) Representação da demarcação dos locais seccionados para obtenção dos blocos de dentina: (a) Plano sagital do slice; (b) Plano frontal do slice; (F) Bloco de dentina obtido após a secção do slice; (G e H) Blocos em BHI evidenciando ausência de bactérias por meio de análise visual, ausência de turbidez.

\section{Padronização do indicador bacteriano}

A cepa bacteriana utilizada neste estudo foi o Enterococcus faecalis (ATCC 29212) inoculada em 7 mL de infusão cérebro coração (BHI, Difco Laboratories, Detroit, EUA) e incubada a $37^{\circ} \mathrm{C}$ por 24 horas. Vinte e quatro horas antes da contaminação dos espécimes, as bactérias foram novamente cultivadas na superfície do $\mathrm{BHI}$ ágar seguindo as mesmas condições de incubação. O inóculo bacteriano foi obtido pela ressuspensão das células em solução salina em uma concentração final de aproximadamente $3 \times 10^{8}$ células $\mathrm{mL}^{-1}$, ajustada para o padrão de turbidez 1 de McFarland padronizada por 
espectrofotômetro UV (Spectrophotometer Model Nova 1600 UV, Piracicaba, SP, Brasil) (ALVES et al., 2015).

\section{Formação do biofilme na superfície do bloco de dentina}

Após o inóculo bacteriano ter sido padronizado, $0,1 \mathrm{~mL}$ de suspensão de Enterococcus faecalis foi distribuído em $5 \mathrm{~mL}$ de $\mathrm{BHI}$ contidos em tubos de ensaio (15x150mm). Em seguida, os blocos de dentina que estavam até o momento em solução salina esterilizada foram transferidos para essa nova solução contendo Enterococcus faecalis. Posteriormente, foram armazenados em estufa a $37^{\circ} \mathrm{C}$ durante cinco dias para permitir a fixação bacteriana.

Dez blocos foram mantidos contaminados durante todo o experimento como controle positivo para verificar a viabilidade bacteriana, enquanto 10 blocos não contaminados foram mantidos em $5 \mathrm{~mL}$ de $\mathrm{BHI}$ esterilizado como controle negativo para assegurar a esterilidade da amostra (Figura 2).

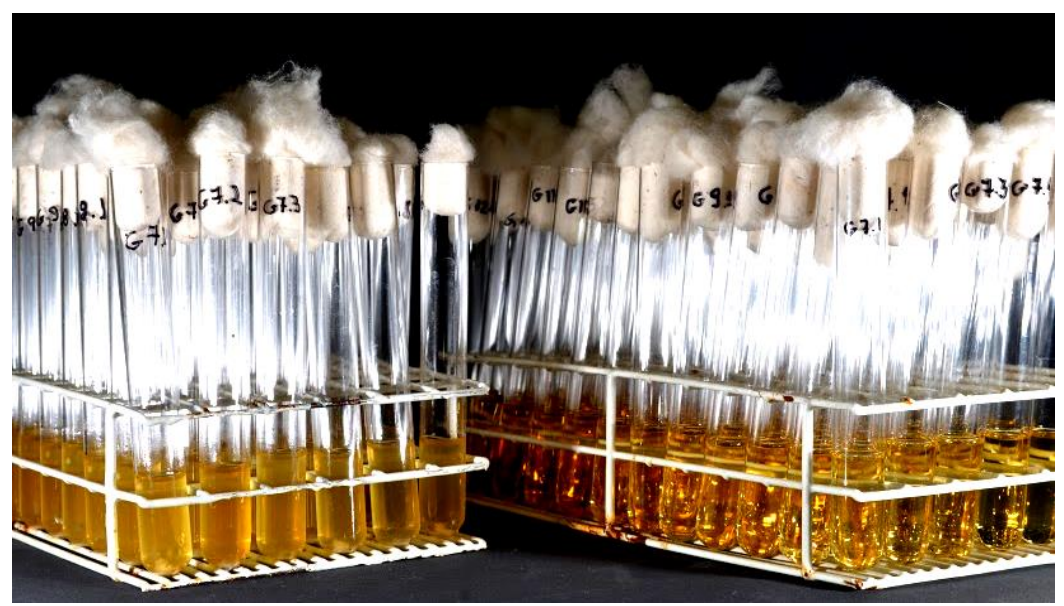

Figura 2. Amostras contaminadas com E. faecalis em $\mathrm{BHI}$ à esquerda (presença de turbidez) e meio de cultura estéril á direita (ausência de turbidez).

Após fixação bacteriana nos blocos de dentina, foi realizada a leitura utilizando espectrofotômetro UV (Spectrophotometer Model Nova 1600 UV, 
Piracicaba, SP, Brasil) comparando com o grupo controle negativo que permaneceu esterilizado durante todo o experimento. O espectrofotômetro UV permite ajustar o meio BHI sem contaminação como sendo o valor zero.

Quanto maior a quantidade de células no meio, maior será a absorção e dispersão de luz fazendo com que o leitor marque números maiores. Após a realização da leitura no espectrofotômetro de todas as amostras, garantindo a contaminação das mesmas, os espécimes foram então distribuídos aleatoriamente em dez grupos, de acordo com o tratamento de superfície a que foram submetidos (Figura 3).

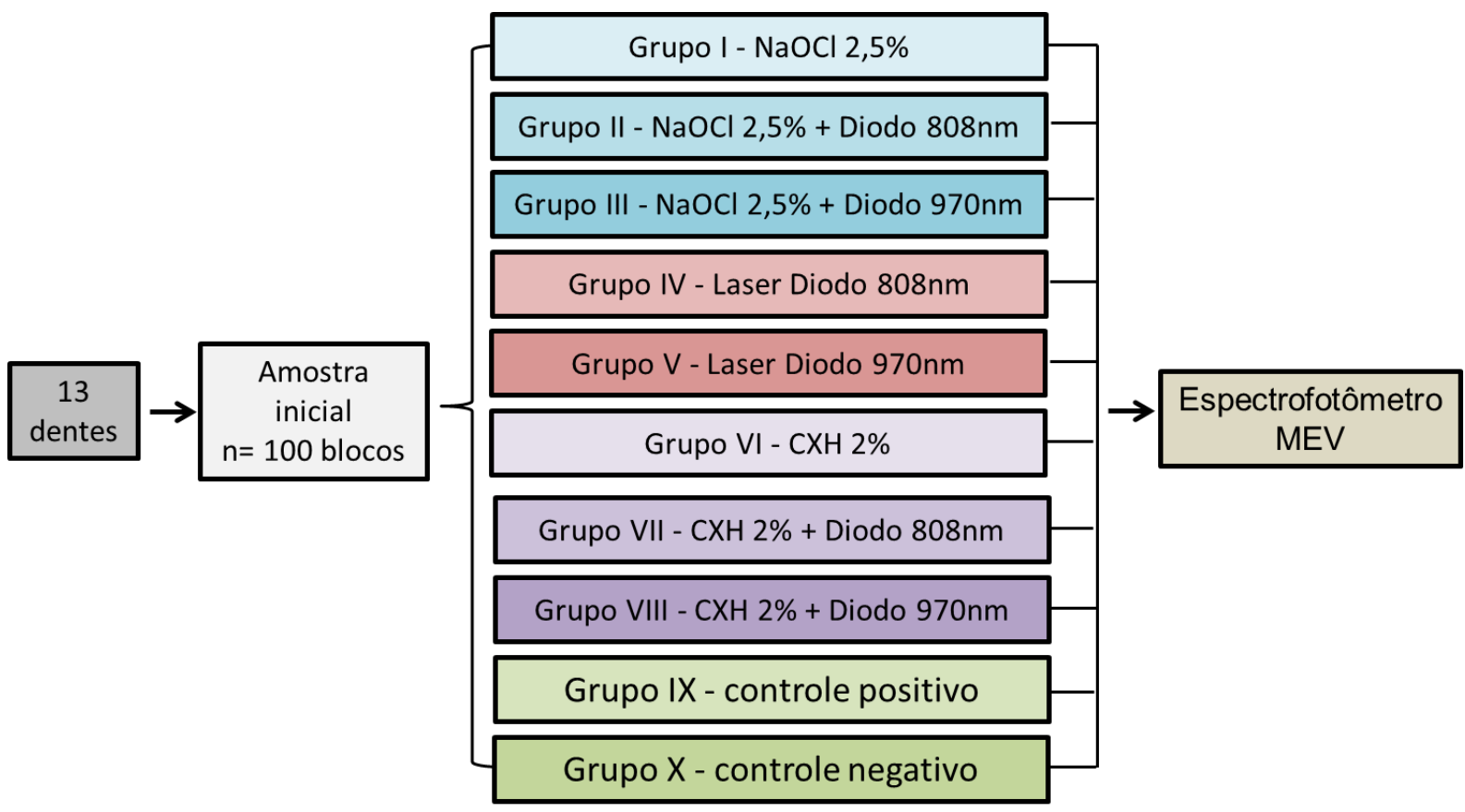

Figura 3. Fluxograma - Distribuição dos grupos experimentais.

Os tubos de ensaio foram abertos e flambados (Figura 4A) para evitar contaminação ao remover os blocos com auxílio de swab (Figura 4B). Cada bloco foi capturado com pinça anatômica 14 mm (Dissecação, Golgran, São Paulo, SP, Brasil) para realização de cada tratamento de superfície. 
Os grupos tratados com hipoclorito de sódio (grupo I, II e III) foram imersos em 5 mL de hipoclorito de sódio à 2,5\% (Fitofarma, Lt. 20442, Goiânia, GO, Brasil) contidos na placa Petri (K13-0035, KASVI, Goiânia, Brasil), durante 5 minutos (Figura 4C). Em seguida, os blocos foram capturados com pinça e transferidos para uma compressa de gaze sobre outra placa de Petri para remoção do excesso de hipoclorito de sódio (Figura 4D).
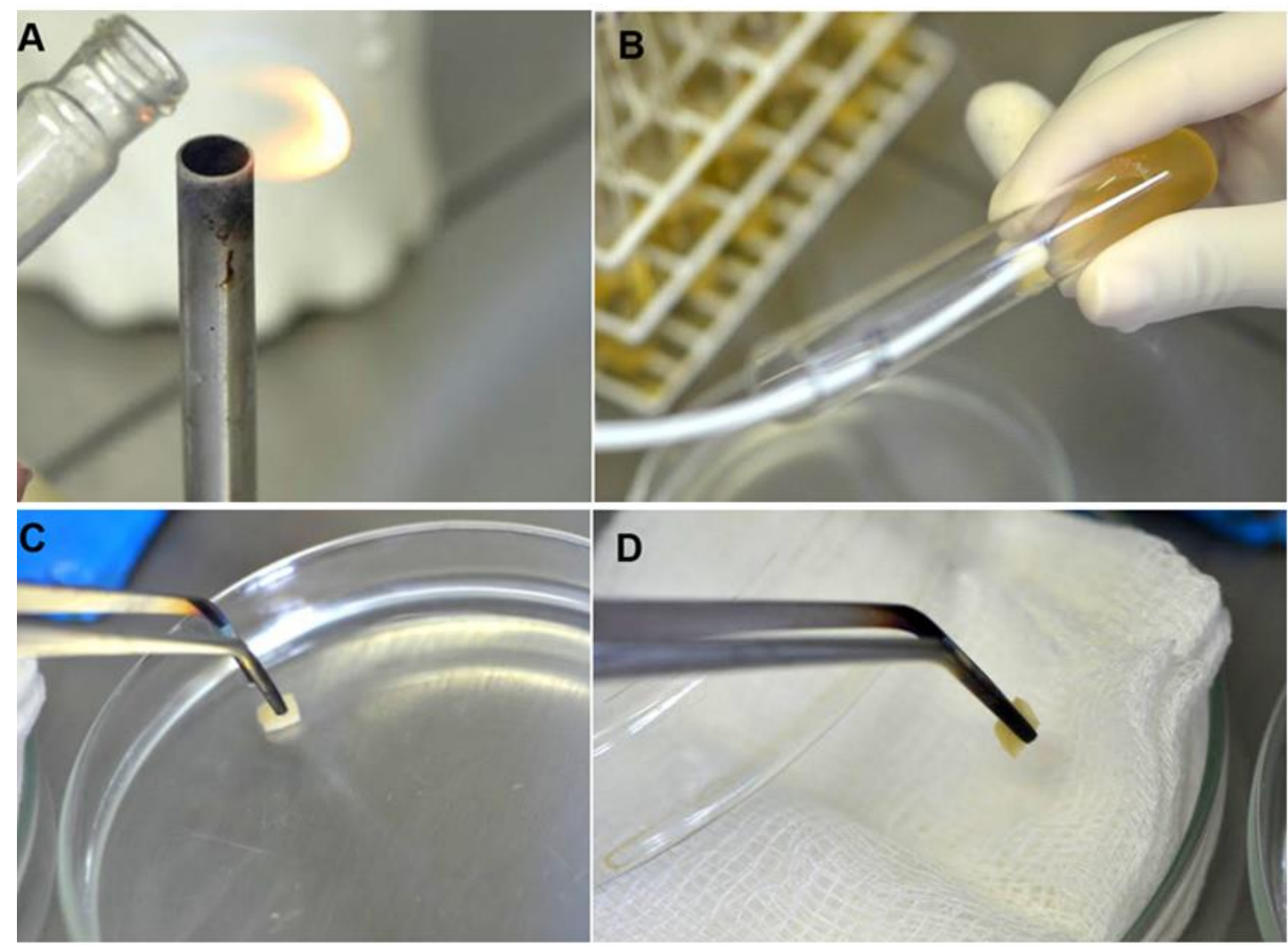

Figura 4. Tratamento realizado com hipoclorito de sódio 2,5\% (A) Flambagem do tubo de ensaio; (B) Captura da amostra com auxílio do swab; (C) Amostra imergida no hipoclorito de sódio $2,5 \%$ em placa petri esterilizada; e (D) Remoção do excesso de hipoclorito de sódio $2,5 \%$. 
Tabela 1. Parâmetros estabelecidos para utilização do laser Diodo.

\begin{tabular}{ccc}
\hline Parâmetros & Laser Diodo $\mathbf{8 0 8} \pm \mathbf{1 0 ~ \mathbf { ~ m }}$ & Laser Diodo $\mathbf{9 7 0} \pm \mathbf{1 5} \mathbf{~ n m}$ \\
\hline Diâmetro da ponta de fibra óptica & $200 \mu \mathrm{m}$ & $200 \mu \mathrm{m}$ \\
Modo de aplicação & Contínuo & Contínuo \\
Duração & 20 segundos & 4 segundos \\
Potência & $2 \mathrm{~W}$ & $2 \mathrm{~W}$ \\
Densidade de Energia & $31,847 \mathrm{~J} / \mathrm{cm}^{2}$ & $159,23 \mathrm{~J} / \mathrm{cm}^{2}$ \\
\hline
\end{tabular}

O grupo II após imersão em hipoclorito de sódio à 2,5\% a dentina intrarradicular foi irradiada com laser 808 nm (DMC Whitening Lase II, São Carlos, SP, Brasil) (Figura 5), com ponta de fibra óptica de diâmetro de $200 \mu \mathrm{m}$ perpendicularmente à superfície e em contato com a mesma, em todas as faces do bloco dentinário. Em cada face foi realizada a irradiação com luz em modo contínuo (100mW), potência de $0,1 \mathrm{~W}$, durante 20 segundos, totalizando $2 \mathrm{~W}$, com densidade de energia $31,847 \mathrm{~J} / \mathrm{cm}^{2}$.
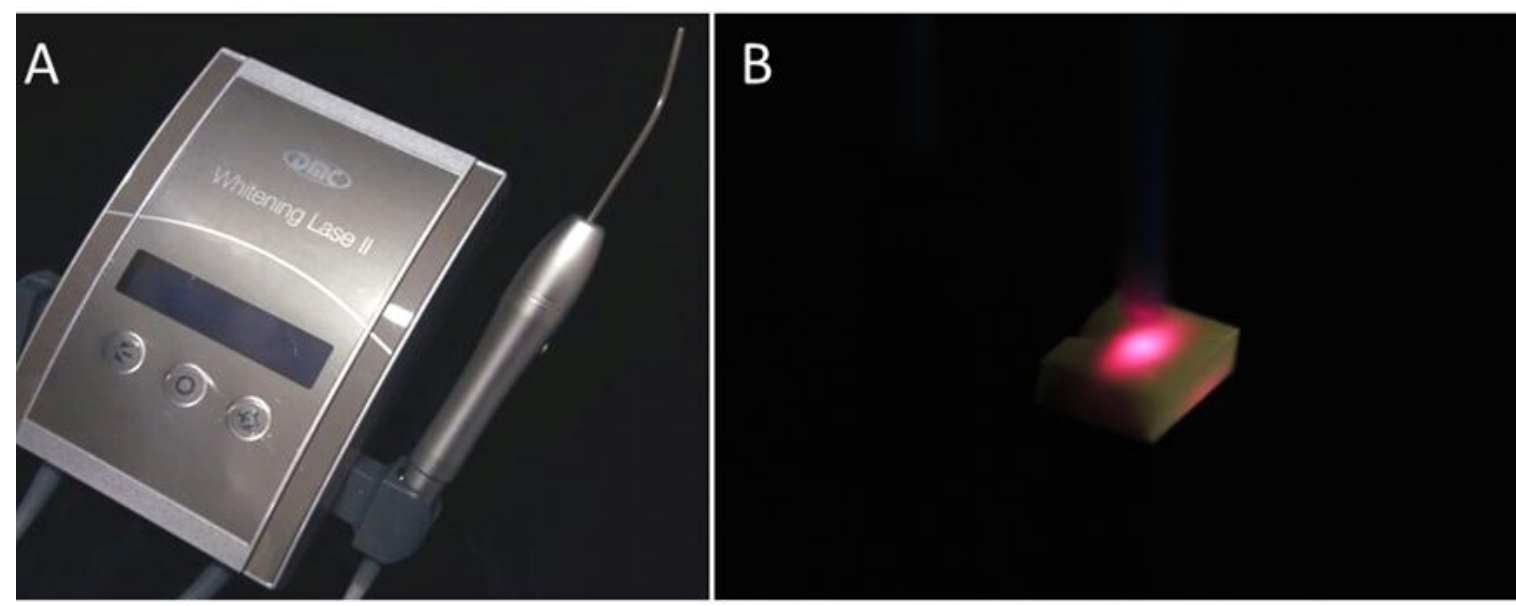

Figura 5. (A) Laser diodo com comprimento de onda 808nm, (DMC Whitening Lase II, São Carlos,SP, Brasil); (B) Tratamento realizado com a ponta de diâmetro $200 \mu \mathrm{m}$ do laser diodo $808 \mathrm{~nm}$. 
Já o grupo III após passar pelo mesmo processo de imersão que o grupo II, foi irradiada com laser diodo 970nm (Sirona Dental, Benshein, HE, Alemanha) (Figura 6) com ponta de fibra óptica de diâmetro de $200 \mu \mathrm{m}$ perpendicularmente à superfície, em todas as faces do bloco dentinário. Em cada face foi realizada a irradiação com luz em modo contínuo, potência de $0,5 \mathrm{~W}$, durante 4 segundos, totalizando $2 \mathrm{~W}$, com densidade de energia $159,23 \mathrm{~J} / \mathrm{cm}^{2}$.

As pontas de ambos os lasers foram analisadas entre as aplicações, com auxílio de lupa, a fim de observar a presença de danos em sua superfície. Quando a superfície se apresentou irregular ou queimada, a ponta foi cortada, para não prejudicar a próxima irradiação.

As amostras dos grupos VI, VII e VIII foram imersas em clorexidina $2 \%$ e passaram pelo mesmo processo de imersão descrito no tratamento com $\mathrm{NaOCl}$. Sendo que o grupo VII foi irradiado com laser 808 nm e o grupo VIII irradiado com laser 970 nm de acordo com os parâmetros previamente descritos.

Dez blocos do grupo IX foram mantidos contaminados durante todo o experimento para verificar a viabilidade bacteriana e mantido em estufa $3^{\circ}{ }^{\circ} \mathrm{C}$ (controle positivo). Enquanto isso, 10 blocos do grupo $\mathrm{X}$ foram armazenados em $5 \mathrm{~mL}$ de $\mathrm{BHI}$ esterilizado para assegurar a esterilidade da amostra em estufa $37^{\circ} \mathrm{C}$ (controle negativo).
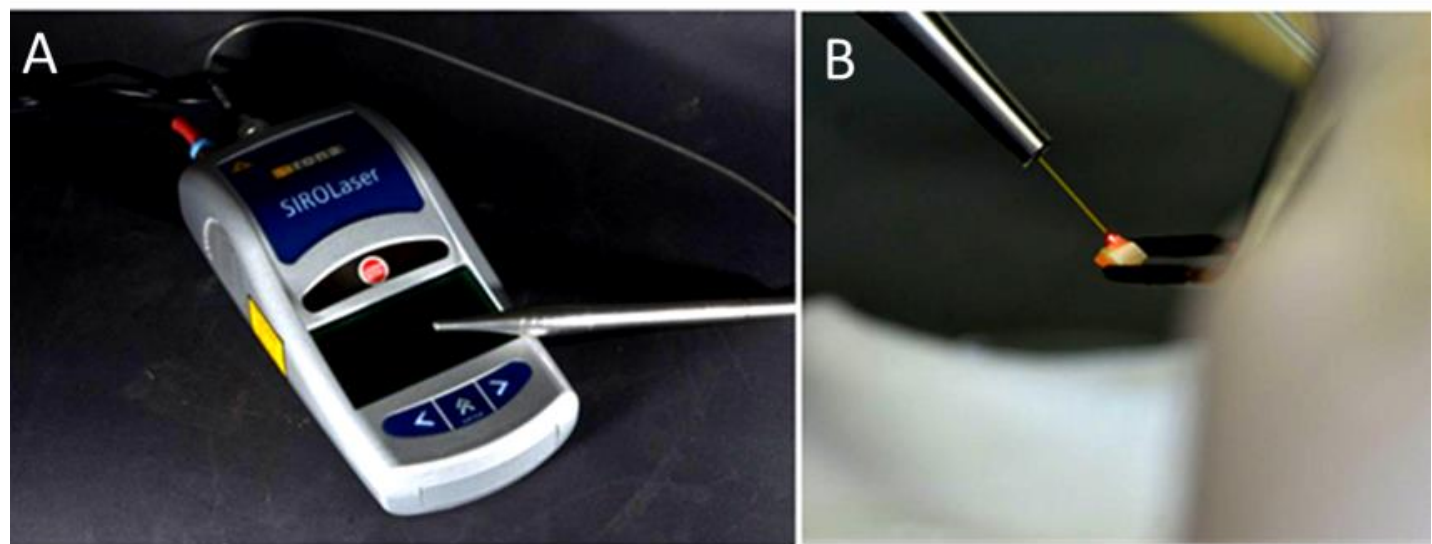

Figura 6. (A) Laser diodo com comprimento de onda 970nm, (Sirolaser, Sirona, Bensheim Germany); (B) Tratamento realizado com a ponta de diâmetro $200 \mu \mathrm{m}$ do laser diodo 970nm. 
Após os tratamentos de superfície de dentina, os blocos foram armazenados em $7 \mathrm{ml}$ de $\mathrm{BHI}$ em estufa à $37^{\circ} \mathrm{C}$ por 48 horas. Em seguida, cada bloco foi transferido para um tubo contendo $7 \mathrm{~mL}$ de $\mathrm{BHI}$ adicionado com neutralizantes Tween 80 e tiossulfato de sódio (P.A., Laboratório Art, Campinas, SP, Brasil) e incubados a $37^{\circ} \mathrm{C}$ durante 48 horas.

\section{Análise microbiológica}

Os blocos de dentina foram incubados a $37^{\circ} \mathrm{C}$ por 48 horas. $\mathrm{O}$ crescimento microbiano foi analisado pela turbidez do meio de cultura. Esse método é baseado na dispersão da luz ao passar por uma amostra. As células em suspensão absorvem e a dispersão da luz que passa através delas faz com que uma cultura pareça turva à observação visual. De fato, a quantidade da luz absorvida e dispersada é proporcional à massa de células no trajeto luminoso. Para as medidas turbidimétricas da massa celular foi utilizado espectrofotômetro UV.

$\mathrm{Na}$ análise microbiológica, um inóculo de $0,1 \mathrm{~mL}$ obtido do $\mathrm{BHI}$ foi transferido para $5 \mathrm{~mL}$ de Letheen Broth sob condições de incubação idênticas. A coloração de Gram foi usada nas culturas de BHI para verificar a contaminação e crescimento, sendo examinado microscopicamente.

A concentração microbiana foi analisada utilizando espectrofotômetro UV (Spectrophotometer Model Nova 1600 UV, Piracicaba, SP, Brasil) (Figura 7) ajustado para leitura em comprimento de onda $\lambda=600 \mathrm{~nm}$, adotando-se como padrão a escala 1 de McFarland, que corresponde à absorbância de 0,137 nm após leitura zero do meio de cultura esterilizado e em temperatura ambiente. 


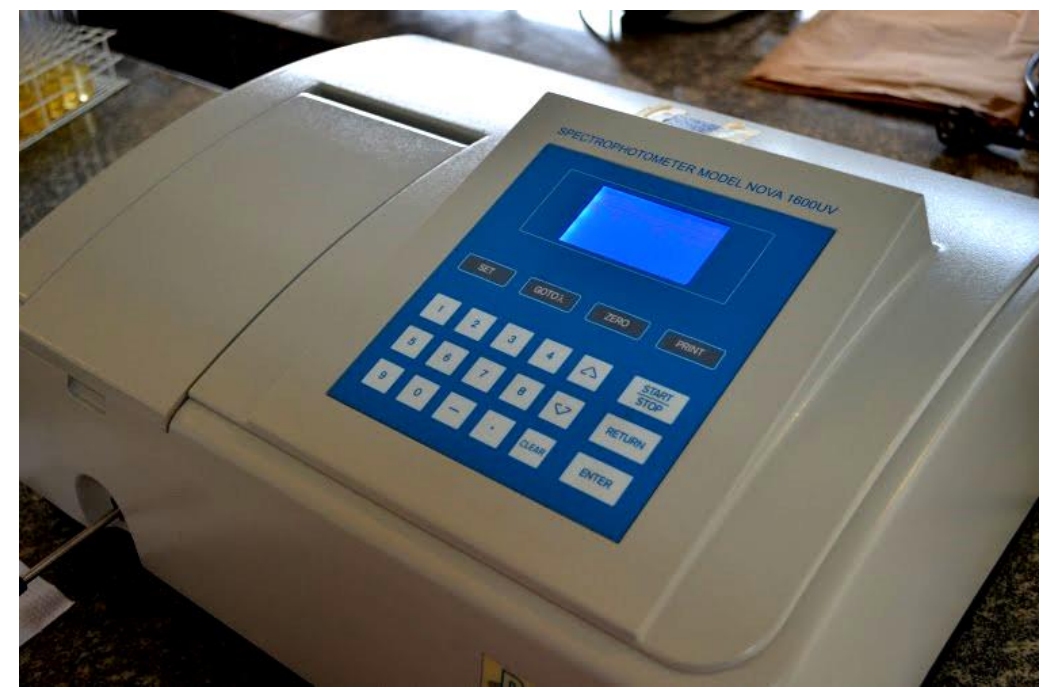

Figura 7. Espectrofotômetro UV (Spectrophotometer Model Nova 1600, UV, Piracicaba, Brasil).

\section{Avaliação ultraestrutural da dentina por meio de microscopia eletrônica de varredura (MEV)}

Cinco amostras de cada grupo foram selecionadas aleatoriamente e submetidas à microscopia eletrônica de varredura (MEV) para análise dos túbulos dentinários e da camada de smear na superfície dentinária. As amostras foram fixadas em solução tamponada e submetidas a uma série de banhos de crescentes concentrações de etanol $\left(25^{\circ}, 50^{\circ}, 75^{\circ}\right.$ por 20 minutos em cada, $95^{\circ}$ por 30 minutos e $100^{\circ}$ por 1 hora). Em seguida, os espécimes foram fixados em cilindros metálicos e então metalizadas por meio de uma fina camada de ouro de $~ 300 \AA$ em metalizadora (Jeol, JSM - 6610, equipado com EDS, Thermo scientific NSS Spectral Imaging, Tóquio, Japão) (Figura 8A) do Laboratório de Microscopia (Labimic) da Universidade Federal de Goiás, GO, Brasil.

Para a realização da análise qualitativa, foi realizada através do microscópio eletrônico de varredura (JSM-IT300, Joel, Tóquio, Japão) (Figura 8B) fotomicrografias da dentina intrarradicular com aumento de 1500X e outra com 5000X para cada amostra, totalizando 10 imagens para cada grupo. Foram observados os seguintes aspectos da superfície dentinária: abertura ou obliteração dos túbulos dentinários, superfície regular ou irregular, presença ou ausência de fibras colágenas e presença ou ausência de biofilme. 

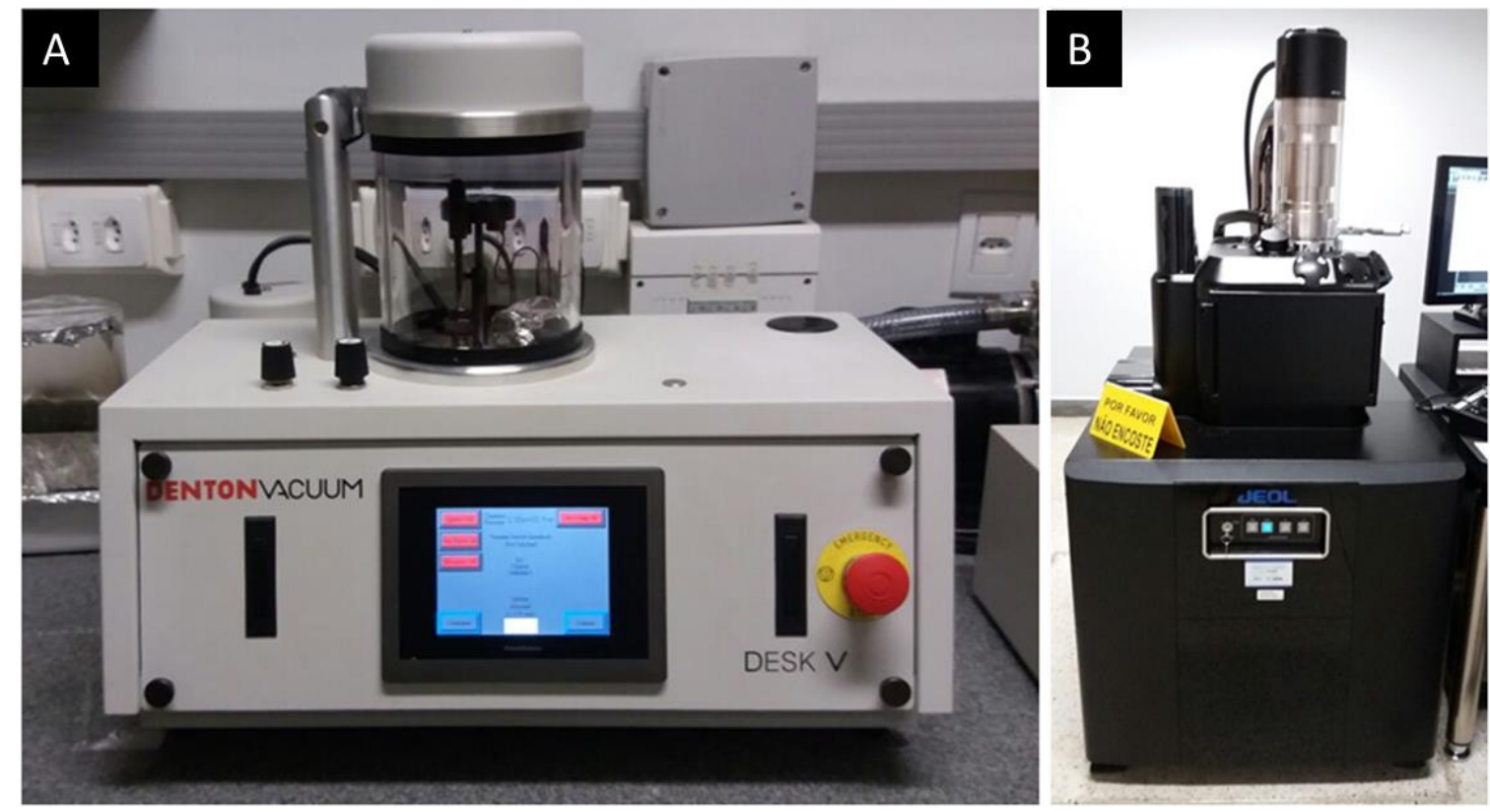

Figura 8. (A) Metalizadora (Jeol, JSM - 6610, equipado com EDS, Thermo scientific NSS Spectral Imaging, Tóquio, Japão); (B) Microscópio eletrônico de varredura (JSM-IT300, Joel, Tóquio, Japão).

\section{Análise estatística}

Uma vez que os dados dos tratamentos da superfície de dentina apresentaram distribuição normal (Shapiro-Wilk, p>0,05) e homogeneidade de variância (teste de Levene, $p>0,05$ ), foram utilizados testes paramétricos para a análise estatística. A análise de variância (ANOVA um fator) foi utilizada para avaliar a influência dos protocolos de desinfecção na porcentagem de diminuição do contingente de Enterococcus faecalis. Foi utilizado o teste de Tukey para comparações entre os grupos. O nível de probabilidade foi de $95 \%$ e todas as análises foram realizadas no software SPSS. 

Resultados 

Ao analisar todos os blocos antes dos tratamentos de forma visual e por espectrofotometria, revelou-se contaminação com exceção dos blocos que mantiveram esterilizados (grupo controle negativo) demonstrando a eficácia do procedimento de contaminação bacteriana (Tabela 2).

Tabela 2. Média e desvio padrão da atividade microbiana $(\mathrm{nm})$ antes e após tratamento de superfície dentinária e análise visual da contaminação bacteriana antes tratamento (CB1) e após tratamento (CB2).

\begin{tabular}{|c|c|c|c|c|}
\hline $\begin{array}{c}\text { Tratamentos de superfície } \\
\text { dentinária }\end{array}$ & $\begin{array}{l}\text { CB1 } \\
\mathrm{n}=10\end{array}$ & $\begin{array}{c}\text { Média e desvio padrão da densidade } \\
\text { óptica }(\mathrm{nm})\end{array}$ & $\begin{array}{l}\text { CB2 } \\
\mathrm{n}=10\end{array}$ & Média da densidade óptica $(\mathrm{nm})$ \\
\hline $\mathrm{NaOCl} 2,5 \%$ & + & $0,8175 \pm 0,082$ & + & $0,1754 \pm 0,102$ \\
\hline $\begin{array}{c}\mathrm{NaOCl} 2,5 \%+\text { Diodo } \\
808 \mathrm{~nm}\end{array}$ & + & $0,8081 \pm 0,061$ & + & $0,2220 \pm 0,100$ \\
\hline $\begin{array}{c}\mathrm{NaOCl} 2,5 \%+\text { Diodo } \\
970 \mathrm{~nm}\end{array}$ & + & $0,7718 \pm 0,081$ & + & $0,2427 \pm 0,072$ \\
\hline Laser diodo 808nm & + & $0,8473 \pm 0,034$ & + & $0,3474 \pm 0,205$ \\
\hline Laser diodo 970nm & + & $0,8711 \pm 0,077$ & + & $0,2745 \pm 0,072$ \\
\hline $\mathrm{CHX} 2 \%$ & + & $0,8229 \pm 0,073$ & + & $0,3090 \pm 0,029$ \\
\hline CHX 2\% + Diodo 808nm & + & $0,8326 \pm 0,032$ & + & $0,2696 \pm 0,020$ \\
\hline $\mathrm{CHX} 2 \%$ + Diodo $970 \mathrm{~nm}$ & + & $0,7902 \pm 0,025$ & + & $0,3224 \pm 0,031$ \\
\hline Controle positivo & + & $0,7974 \pm 0,045$ & + & $0,7918 \pm 0,144$ \\
\hline Controle negativo & - & $0 \pm 0$ & - & $0 \pm 0$ \\
\hline
\end{tabular}

O símbolo mais e menos corresponde a análise visual; (+) representa turbidez do meio, (-) ausência de turbidez. Cada sinal positivo ou negativo corresponde uma amostra analisada. 


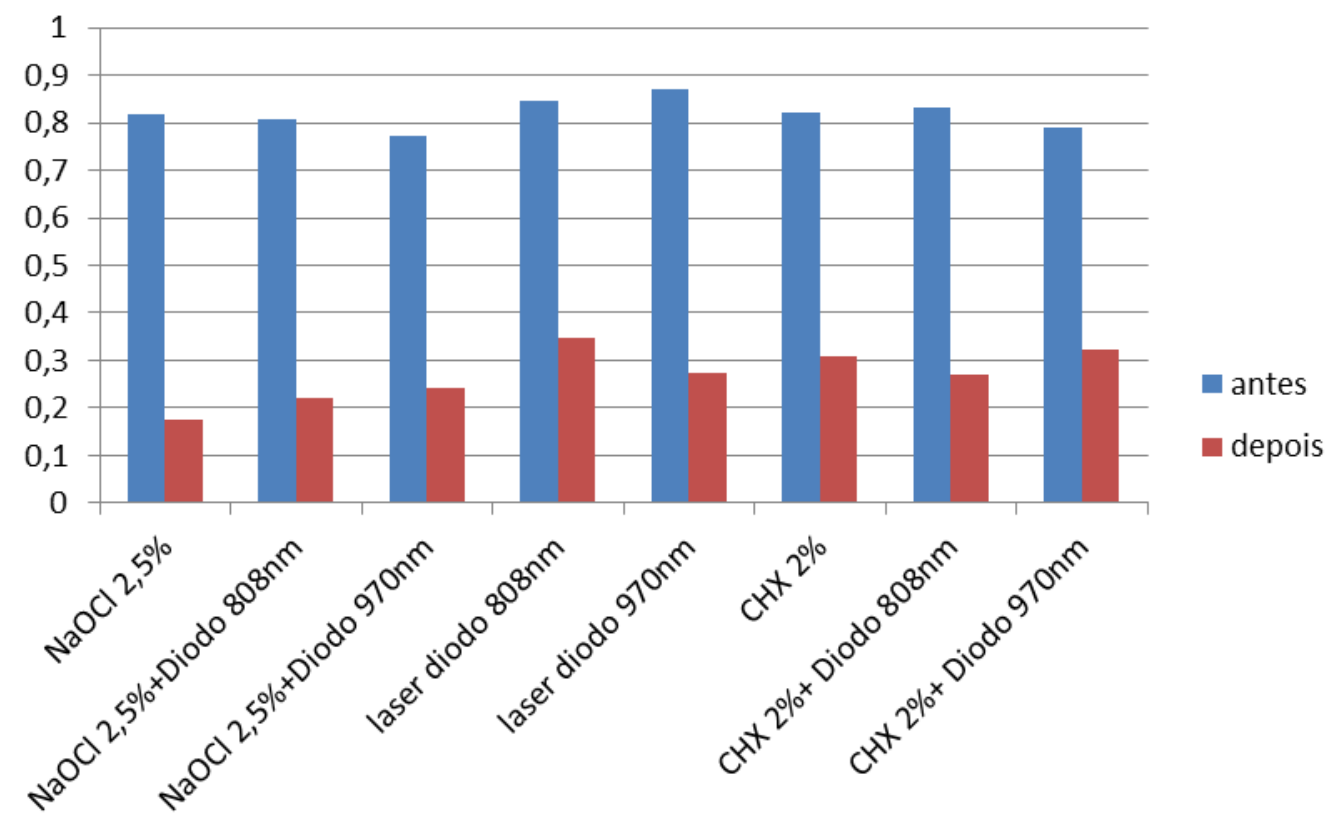

Figura 9. Média da atividade antimicrobiana $(\mathrm{nm})$ antes e após os tratamentos.

Através da análise da atividade microbiana antes e após os tratamentos da superfície dentinária, pode-se observar diferença estatística significante $(p<0,05)$ para todos os tratamentos, exceto para os blocos que mantiveram contaminados (grupo IX- controle positivo) e blocos que permaneceram esterilizados (grupo Xcontrole negativo). Portanto, os tratamentos realizados diminuíram significativamente o número de bactérias.

Ao analisar a porcentagem da atividade antimicrobiana $(\mathrm{nm})$ antes e após os tratamentos de superfície, observa-se que o tratamento com $\mathrm{NaOCl} 2,5 \%$ (grupo I) apresentou o maior porcentual de diminuição da atividade antimicrobiana $(77,5 \pm$ $12,1)$ semelhante estatisticamente aos grupos II ( $\mathrm{NaOCl} 2,5 \%$ + laser diodo $808 \mathrm{~nm})$ $(68,7 \pm 8,7)$, III $(\mathrm{NaOCl} 2,5 \%$ + laser diodo $970 \mathrm{~nm})(68,7 \pm 8,7)$, grupo $\mathrm{V}$ (laser diodo 970nm) (68,3 $\pm 8,7)$, VI (CHX 2\%) (62,0 $\pm 5,5)$, VII (CHX 2\% + laser diodo 808nm) $(67,5 \pm 3,3)(p>0,05)$. E diferente estatisticamente do grupo IV (laser diodo 808nm) $(58,8 \pm 25,0)$, VIII $(\mathrm{CHX} 2 \%$ + diodo $970 \mathrm{~nm})(59,2 \pm 4,0)$ e grupos controles $(p<0,05)$ (Tabela 2 e Figura 10). 
Tabela2. Valores da porcentagem de redução do contingente bacteriano e desvio padrão.

Tratamentos de superfície dentinária

$\mathrm{NaOCl} 2,5 \%$

$\mathrm{NaOCl} 2,5 \%$ + Diodo 808nm

NaOCl 2,5\% + Diodo 970nm

Laser diodo 808nm

Laser diodo 970nm

$\mathrm{CHX} 2 \%$

$\mathrm{CHX} 2 \%$ + Diodo 808nm

CHX 2\% + Diodo 970nm
Média da densidade óptica $(\mathrm{nm})$

$$
77,5 \pm 12,1(68,8-86,1) \mathbf{A}
$$$$
72,5 \pm 12,2(63,6-81,5) \mathbf{A B}
$$$$
68,7 \pm 8,7(62,3-74,8) \mathbf{A B}
$$

$58,8 \pm 25,0(41,0-76,7)$ B

$68,3 \pm 8,7(62,1-74,5) \mathbf{A B}$

$62,0 \pm 5,5(58,2-66,0) \mathrm{AB}$

$67,5 \pm 3,3(55,1-69,9) \mathrm{AB}$

$59,2 \pm 4,0(56,4-62,0) \mathbf{B}$

Letras maiúsculas diferentes indicam diferença estatística dos tratamentos de superfície dentinária na redução do contingente bacteriano ao teste de Tukey $(p<0,05)$.

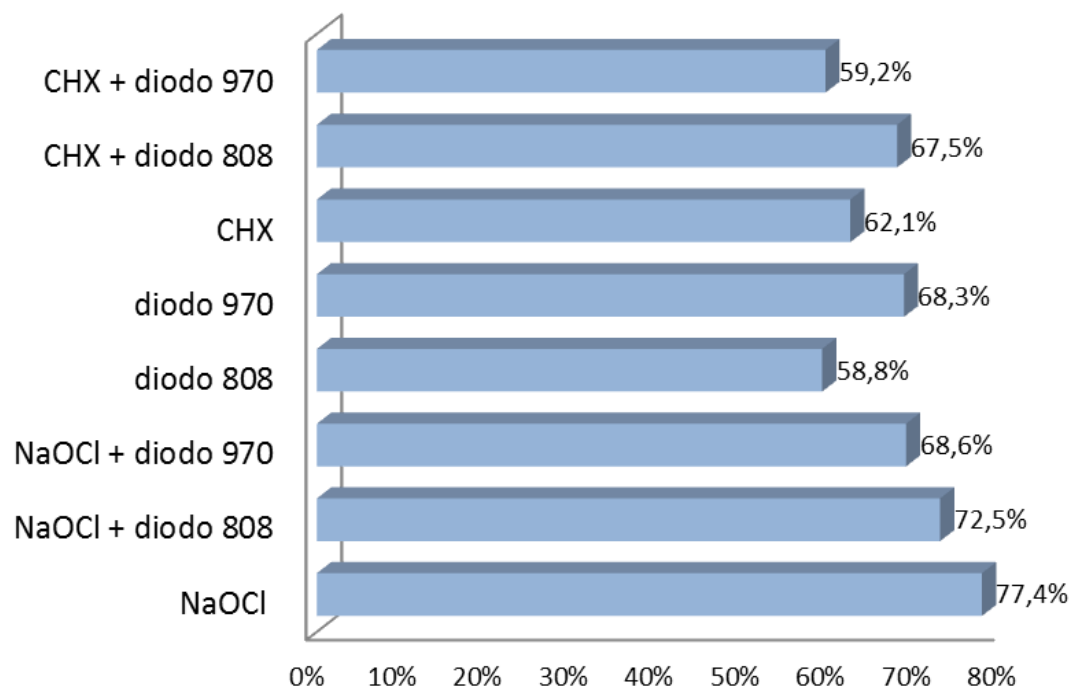

Figura 10. Porcentagem da diminuição da atividade antimicrobiana após o tratamento. 


\section{Avaliação ultraestrutural da dentina por meio de microscopia eletrônica de varredura (MEV)}

A análise qualitativa das imagens obtidas por meio do microscópio eletrônico de varredura revelou no grupo controle negativo (Figura 11/AB) túbulos dentinários com contorno aberto e regular. A dentina intertubular se mostrou regular, livre de detritos e bactérias. O grupo que manteve contaminado durante todo o tratamento (controle positivo) (Figura 11IIAB) revelou biofilme denso cobrindo a superfície dentinária. As aberturas dos túbulos dentinários se apresentaram obliteradas.

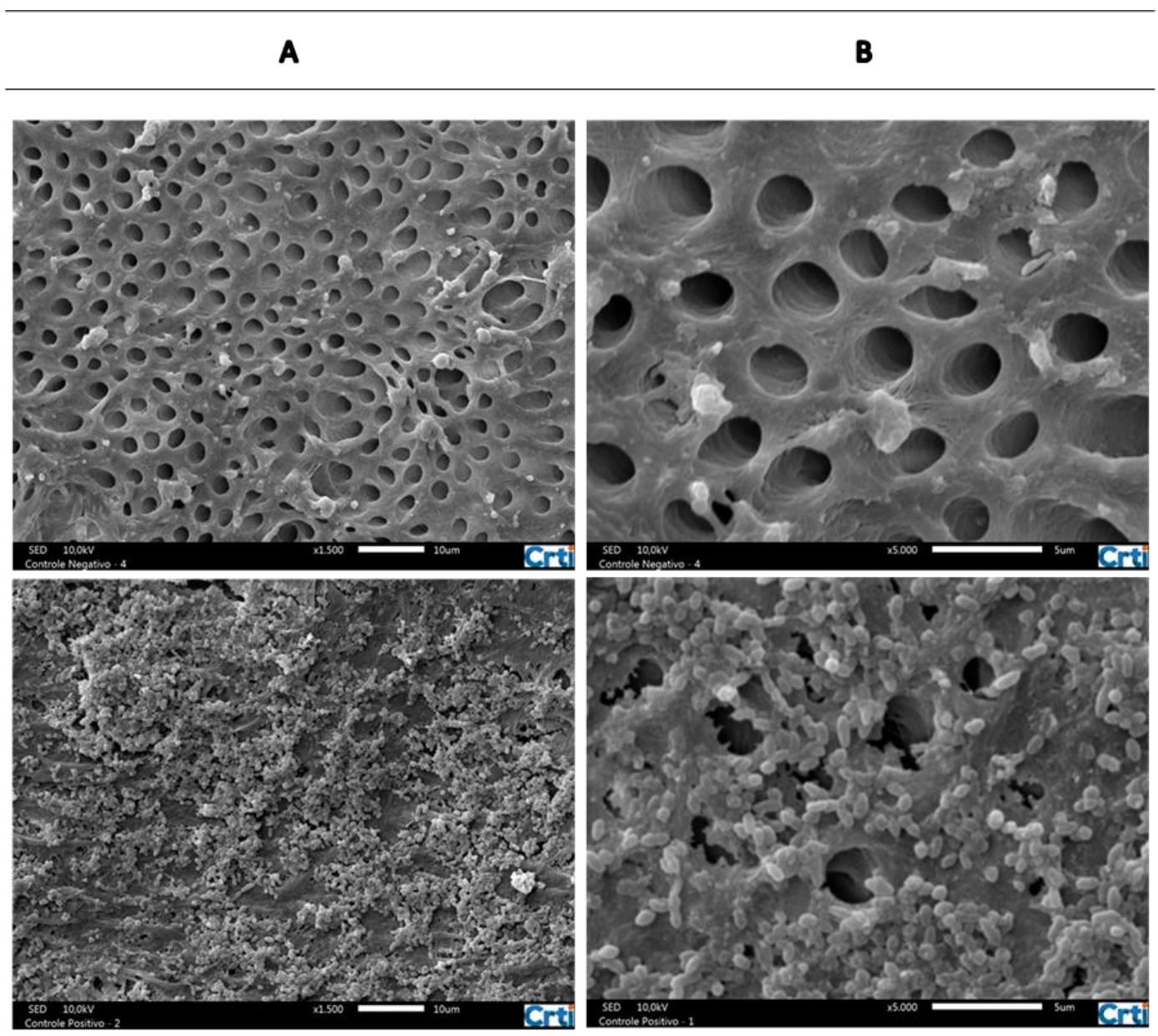

Figura 11. Imagens da microscopia eletrônica de varredura em diferentes aumentos. A aumento de 1500x; B - aumento de 5000x. I - controle negativo; II - controle positivo.

A dentina submetida ao tratamento com hipoclorito de sódio 2,5\% (Figura $12 \mathrm{AB})$ apresentou regiões com erosão da dentina intertubular com uma superfície 
dentinária irregular com biofilme disperso. Já o tratamento da superfície com solução de clorexidina $2 \%$ (Figura $12 \mathrm{IIAB}$ ) revelou biofilme denso cobrindo a superfície, impossibilitando a visualização das possíveis alterações que a solução poderia causar à superfície dentinária.

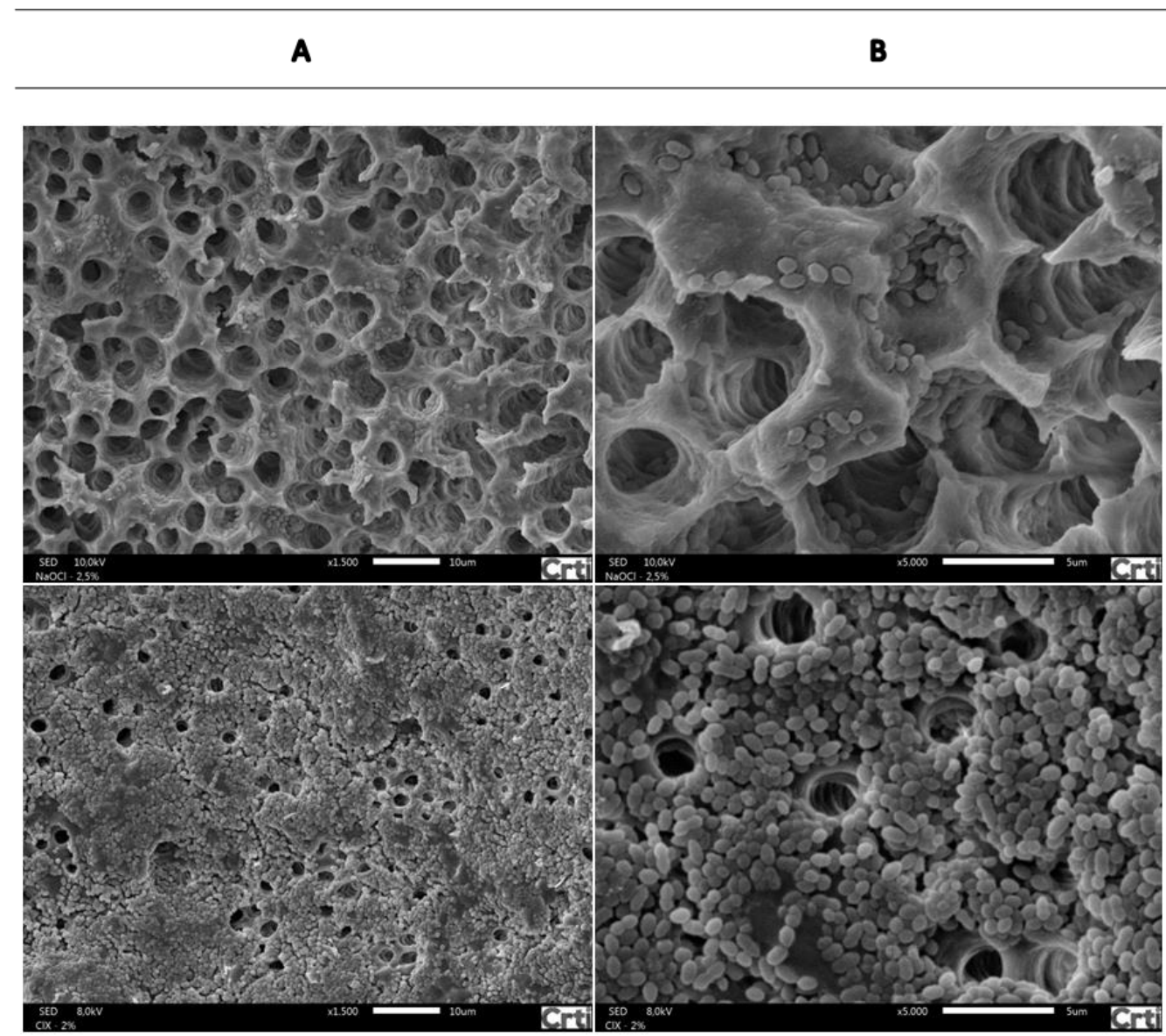

Figura 12. Imagens da microscopia eletrônica de varredura em diferentes aumentos. A - - aumento de 1500x; B - aumento de 5000x; I - tratamento com hipoclorito de sódio $2,5 \%$; II - tratamento com clorexidina $2 \%$.

Após a dentina ser irradia com laser diodo $808 \mathrm{~nm}$, observou-se regiões com erosão da dentina intertubular, tornando a superfície dentinária irregular (Figura 13IAB) biofilme disperso. Ao associar o hipoclorito de sódio 2,5\% ao laser $808 \mathrm{~nm}$ (Figura 13IIAB) potencializou o efeito do laser diodo 808nm, apresentando derretimento dentinário e superfície irregular. A dentina submetida ao tratamento de 
solução de clorexidina $2 \%$ e laser diodo $808 \mathrm{~nm}$ (Figura 13IIIAB) apresentou uma superfície similar a irradiado apenas com clorexidina $2 \%$.

\begin{tabular}{ll}
\hline A & B \\
\hline
\end{tabular}

II

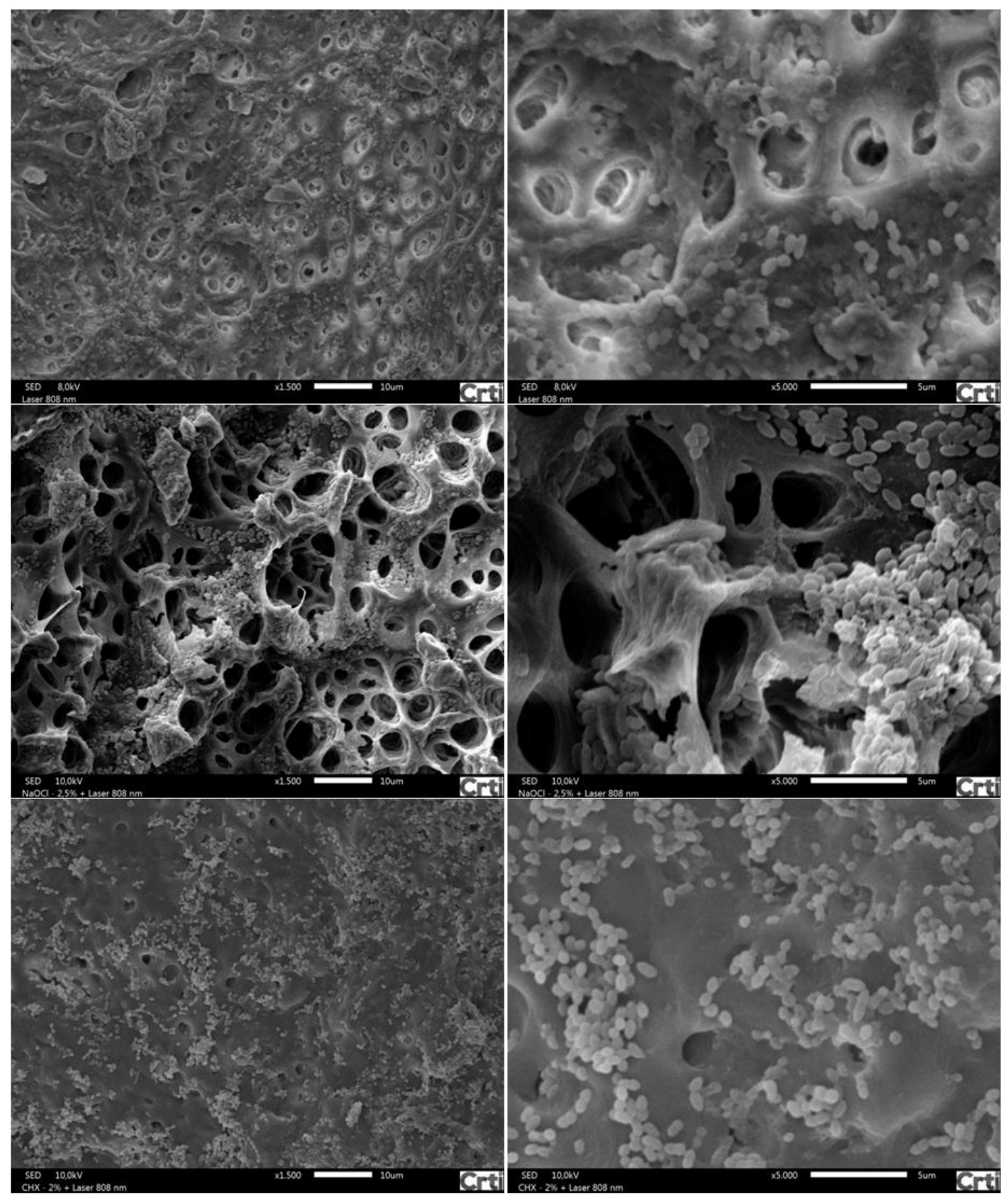

Figura 13. Imagens da microscopia eletrônica de varredura em diferentes aumentos. A aumento de 1500x; B - aumento de 5000x; I - laser diodo 808nm; II - laser diodo 808nm + $\mathrm{NaOCl} 2,5 \%$; III - laser diodo $808 \mathrm{~nm}+\mathrm{CHX} 2,5 \%$. 
Quando submetidos a irradiação laser diodo 970nm, a superfície dentinária apresentou uma matriz orgânica amorfa e derretimento da dentina intertubular com abertura parcial dos túbulos dentinários caracterizando uma superfície irregular (Figura 14IAB) e um biofilme disperso em sua superfície. As imagens obtidas dos blocos de dentina submetidos ao tratamento de hipoclorito $2,5 \%$ e laser diodo 970nm (Figura 14IIAB) com biofilme em sua superfície apresentaram superfície irregular com erosão da dentina intertubular. A dentina submetida ao tratamento de solução de clorexidina 2\% e laser diodo 970nm (Figura 14IIIAB) apresentaram superfície dentinária uma matriz orgânica amorfa com exposição parcial dos túbulos dentinários. 


\section{A}

B
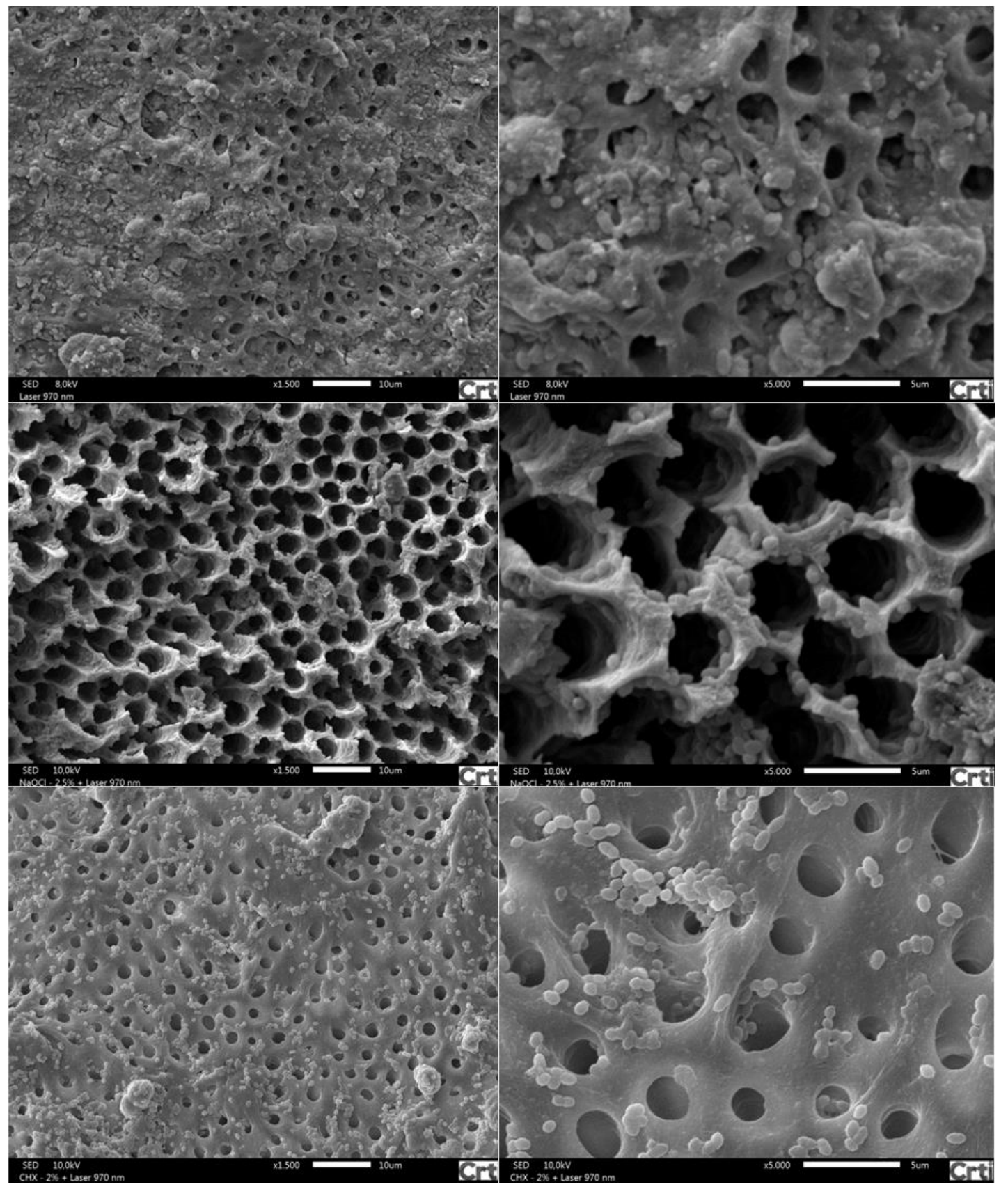

Figura 14. Imagens da microscopia eletrônica de varredura em diferentes aumentos. A aumento de 1500x; B - aumento de 5000x; I - laser diodo 970nm; II - laser diodo 970nm + $\mathrm{NaOCl} 2,5 \%$; III - laser diodo $970 \mathrm{~nm}+\mathrm{CHX} 2,5 \%$ 
$D_{\text {iscussão }}$ 

O processo de desinfecção do sistema de canais radiculares (SCR) tem como finalidade reduzir o contingente bacteriano visando à reparação dos tecidos periapicais (BAZVAND et al., 2014; SAHA; NAIR; ASRANI, 2015), uma vez que a infecção endodôntica não se restringe apenas no canal principal, ocupando também áreas de achatamentos, istmos, reentrâncias e ramificações do SCR. Além disso, a complexa estrutura tubular dentinária, permite a difusão facilitada de substâncias tóxicas e microrganismos para as camadas mais profundas da dentina (RIBEIRO et al., 2010; KANDASWAMY et al., 2010; WONG; CHEUNG, 2014). Nesse sentido, as variações anatômicas somadas às características inerentes à permeabilidade dentinária, limitam a desinfecção do SCR durante o preparo biomecânico e favorecem a persistência de remanescentes teciduais, bem como a manutenção de bactérias (RIBEIRO et al., 2010; KANDASWAMY et al., 2010; SIQUEIRA JR; ROÇAS, 2012; VERSIANI et al., 2016).

Com a finalidade de promover a descontaminação efetiva do SCR, terapias alternativas e coadjuvantes ao tratamento endodôntico foram propostas, como o uso de diferentes tipos de lasers (HMUD et al., 2010; ASNAASHARI et al., 2013; GOMES et al., 2013; ARNEIRO et al., 2014; LLENA et al., 2015; GUTKNECHT et al., 2016; MORAGO et al., 2016), entre eles o laser diodo, que ao atuar em camadas mais profundas da dentina (ALFREDO et al., 2009), permite a redução dos microrganismos no interior do SCR (SCHOOP et al., 2006; KANUMURU et al., 2014; MASHALKAR et al., 2014; ASNAASHARI et al., 2016).

A fim de determinar parâmetros seguros para a utilização do laser diodo, estudos prévios avaliaram os efeitos térmicos e as alterações morfológicas da 
dentina radicular irradiada com lasers diodo 970nm (ALFREDO et al., 2008; LOPES et al., 2016; BEER et al., 2017) e 808nm (DA COSTA-RIBEIRO et al., 2007; ESTIVES-OLIVEIRA et al, 2010) e com parâmetros de potência total de 1,5 à 2,5W atenderam objetivo primordial para o uso de lasers em endodontia, sem ultrapassar aumento de temperatura de $10^{\circ} \mathrm{C}$ acima da temperatura corporal, por mais de 1 minuto (RAMSKOLD; FONG; STROMBERG, 1997). Segundo MORRITZ (1997), a irradiação do laser diodo de baixa potência com $2 \mathrm{~W} / 50 \mathrm{~Hz}$ por 25 segundos foi suficiente para promover a desinfecção do canal radicular. Neste sentido, no presente estudo foi utilizado o laser diodo de diferentes comprimentos de onda com uma potência final de $2 \mathrm{~W}$, sendo que densidade de energia do laser diodo $808 \mathrm{~nm}$ foi de $31,847 \mathrm{~J} / \mathrm{cm}^{2}$; e para laser diodo $970 \mathrm{~nm}$ foi de $159,23 \mathrm{~J} / \mathrm{cm}^{2}$.

Em relação aos tipos de lasers utilizados, os resultados do presente estudo demostraram que o tratamento com laser diodo 970nm apresentou redução do contingente bacteriano $(68,3 \pm 8,7)$ estatisticamente semelhante ao grupo irradiado com laser diodo $808 \mathrm{~nm}(58,8 \pm 25,0)$, corroborando com estudos prévios (BEER et al., 2012; KANUMURU et al., 2014).

A ação antibacteriana do laser diodo 970nm está diretamente relacionada ao aquecimento do substrato dentinário ao qual as bactérias estão ligadas (KANUMURO et al., 2014; GUTKNECHT et al., 2016), e à interação de um sensibilizador fotoativado com o substrato biológico, o que leva à produção de oxigênio altamente reativo, que pode danificar moléculas celulares essenciais, incluindo proteínas, lipídios da membrana e ácido nucleico (BAGO et al., 2013; ASNAASHARI et al., 2016). Segundo SCHOOP et al. (2006), ao avaliarem o 
efeito antibacteriano do laser diodo $980 \mathrm{~nm}$, evidenciaram redução significativa no número de bactérias, principalmente quando irradiado com potência de 1,5W.

Já o laser diodo 808nm atua por meio de repetidas irradiações (MORRITZ et al., 1997). MORRITZ et al. (1997) evidenciaram que as bactérias gramnegativas são atingidas imediatamente após a primeira irradiação, enquanto que as gram positivas, como as E. faecalis avaliadas no presente estudo, precisam ser irradiadas repetidamente para que ocorra a desestruturação da parede celular bacteriana. Assim, apesar da densidade de energia utilizada ser semelhante ao estudo de MORRITZ et al. (1997), no presente trabalho a irradiação foi realizada apenas uma única vez, o que pode justificar menor redução bacteriana quando comparado ao estudo de MORRITZ et al., (1997) que alcançou eliminação quase completa de bactérias na segunda irradiação.

Somado a isso, a dentina é por si só uma estrutura tubular complexa que permite a penetração de microrganismos e substâncias em profundidade (RIBEIRO et al., 2010; LO GIUDICE et al., 2015). Dessa forma, nem o laser, nem as soluções e suas associações avaliadas no presente estudo, foram capazes de alcançar as camadas de dentina mais profundas, não permitindo a eliminação completa das bactérias.

LO GIUDICE et al. (2015) ao analisarem a relação entre área da dentina intertubular e a superfície ocupada pelos túbulos dentinários, concluíram que estes apresentaram maior diâmetro no terço cervical $(4,32 \mu \mathrm{m})$, em relação ao terço médio $(3,74 \mu \mathrm{m})$ e apical $(1,73 \mu \mathrm{m})$. Ainda, a área da dentina intertubular aumentou no sentido ápico-cervical. GUTKNECHT et al. (2000 e 2004), ao avaliarem o efeito do laser diodo em fatias de dentina de $100 \mu \mathrm{m}$ de espessura, 
verificaram redução do contingente bacteriano em torno de 95\% (GUTKNECHT et al., 2000; GUTKNECHT et al., 2004; MEHRVARZFAR et al., 2011).

O presente estudo utilizou blocos de dentina intrarradicular da região cervical de $2 \mathrm{~mm}$ de espessura $(2000 \mu \mathrm{m})$, possibilitando maior penetração e acúmulo bacteriano em profundidade, o que teria proporcionado descontaminação mais superficial, ainda permanecendo bactérias viáveis no interior dos blocos, ao contrário de outros trabalhos que utilizaram dentina com menor espessura (GUTKNECHT et al., 2000; GUTKNECHT et al., 2004; MEHRVARZFAR et al., 2011; SOUZA, 2008; BEER et al., 2012; SOHRABI et al., 2016).

Outro fator que deve ser levado em consideração ao analisar os resultados do presente estudo é em relação à uniformidade de irradiância da luz laser. Assim como ocorre nas unidades de fotopolimerização, a irradiância é mensurada através da potência irradiada dividida pela área de emissão na superfície da ponta do laser (PRICE et al., 2015). Entretanto, a saída irradiante do feixe de luz pode não ser uniforme, apresentando perfil irregular, onde algumas áreas apresentam valores mais altos de irradiância do que outros (PRICE et al., 2015). Dessa forma, o substrato irradiado apresentará pontos não uniformes de irradiação, o que pode interferir de forma direta na eficácia do laser.

Em relação à aplicação do laser diodo $808 \mathrm{~nm}(58,8 \pm 25,0)$, e após irrigação com as soluções de hipoclorito de sódio a 2,5\% (72,5 \pm 12,2) e clorexidina a $2 \%(67,5 \pm 3,3)$ não foi possível observar melhora significativa na redução do contingente bacteriano. Estes resultados corroboram com MEHRVARZFAR et al. (2011), que ao analisarem o efeito do laser diodo 808nm 
isolado e em combinação com as soluções de hipoclorito de sódio, clorexidina e MTDA em canais radiculares infectados, não observou diferenças estatísticas entre os grupos.

mesmo foi observado ao analisar a associação do laser diodo 970nm com solução de clorexidina a $2 \%(59,2 \pm 4,0)$ e hipoclorito de sódio $2,5 \%(68,7 \pm$ 8,7) havendo semelhança estatística ao laser diodo 970nm empregado isoladamente $(68,3 \pm 8,7)$. Resultados concordantes ao estudo realizado por CASTELO-BAZ et al. (2012), que verificaram que o uso de solução irrigante associada a irradiação de laser diodo de alta potência foi estatisticamente semelhante ao laser empregado de forma isolada. Estes resultados evidenciam que mesmo após a aplicação das soluções irrigantes, o laser diodo 970nm e $808 \mathrm{~nm}$ não foram capazes de atingir profundidade suficiente para eliminar todo o contingente bacteriano.

BEER et al. (2012) compararam o efeito antibacteriano do laser diodo de alta $(940 \mathrm{~nm})$ e baixa potência $(810 \mathrm{~nm})$, e evidenciaram redução de $E$. faecalis em torno de $98,6 \%$ e 98,8\%, respectivamente. Os valores de redução do contingente bacteriano encontrados foram mais altos quando comparados ao presente estudo, em que tratamento com laser diodo $808 \mathrm{~nm}$ obteve a menor redução do número de bactérias, 58,8\%, e a aplicação do laser de alta potência resultou em redução $68,3 \%$ Entretanto, as diferenças nos resultados podem estar relacionadas à metodologia, uma vez que o tempo de contaminação no presente estudo foi de 5 dias, como utilizado em estudos recentes que avaliaram a eficácia de diferentes estratégias antibacterianas na formação de biofilme imaturo (WONG; CHEUNG, 2014; GEREK; YAYLALI, 2016), quando comparado com o trabalho de BEER et al. (2012), que realizou a contaminação apenas por 
2 horas. Sendo assim, as bactérias estariam em forma planctônica e não em biofilme, o que permitiu a remoção facilitada pela solução e consequente morte bacteriana.

A fase de desenvolvimento do biofilme na avaliação antimicrobiana é de grande importância e pode ser um fator determinante para a maior resistência a diferentes tipos de estratégias antimicrobianas (PORTENIER et al, 2003; GAD et al., 2004; LIM et al., 2009). Atualmente, grande parte dos estudos avaliam as propriedades antimicrobianas das soluções irrigantes, envolvendo ambas as formas de crescimento bacteriano, planctônico e biofilme (JHAJHARIA et al., 2015). Por outro lado, DE SOUZA et al. (2008) evidenciaram significativa redução de crescimento bacteriano após tratamento com laser diodo ao avaliarem camadas mais superficiais de dentina contaminada nos diferentes terços radiculares, o que difere do presente estudo que avaliou a presença de microrganismos em blocos de dentina com 2 milímetros de espessura.

Em relação às soluções irrigantes empregadas isoladamente, o tratamento com hipoclorito de sódio a 2,5\% evidenciou resultado semelhante em relação à diminuição bacteriana $(77,5 \pm 12,1)$ quando comparado ao grupo tratado com clorexidina a $2 \%(62,0 \pm 5,5)$, concordando com os estudos prévios que avaliaram diferentes concentrações (SIQUEIRA et al., 2007; RÔÇAS et al., 2016, FLACH et al., 2016). As soluções possuem propriedades antimicrobianas, sendo que o hipoclorito de sódio possui a capacidade de promover a desinfecção e solvência de tecidos orgânicos e inorgânicos (ESTRELA et al., 2002; BARATOT-FILHO et al., 2004) e a clorexidina, sendo utilizada com solução alternativa, possui propriedades de substantividade, efeito antimicrobiano prolongado e baixa citotoxicidade (GOMES et al., 2013; 
BAZVAND et al., 2014; MOHAMMADI et al., 2015). Do ponto de vista microbiológico, qualquer solução pode ser utilizada durante o tratamento de dentes infectados. Uma vez que algumas propriedades podem influenciar a escolha da solução auxiliar, tais como a capacidade de dissolução de tecidos do hipoclorito de sódio ou substantividade da clorexidina.

Além da análise microbiológica, o 2presente estudo avaliou também as alterações morfológicas da dentina irradiada, por meio de microscopia eletrônica de varredura (MEV). Estas alterações dependem principalmente dos parâmetros de potência, frequência e modo de aplicação (contínuo ou pulsátil), uma vez que estes estão diretamente relacionados ao aumento da temperatura nos tecidos dentais e à forma de atuação do mesmo no substrato dental avaliado (DA COSTA RIBEIRO et al., 2007; ALFREDO et al., 2008).

A superfície dos blocos de dentina irradiados com laser de baixa potência (808nm) apresentaram-se de forma irregular com regiões de erosão na dentina intertubular, o que difere de outros estudos em que houve a fusão dos túbulos dentinários após aplicação do laser diodo (SHOOP et al., 2006; DA COSTA RIBEIRO et al., 2007; ALFREDO et al.,2009; ESTEVES-OLIVEIRA et al.,2010; BEER et al., 2012). Os diferentes resultados podem ser justificados devido a posição de aplicação do laser em relação ao substrato dental a ser irradiado (ALVES et al., 2005). No presente, a aplicação do laser foi perpendicular à superfície dos blocos de dentina, enquanto que nos outros trabalhos apresentados a aplicação foi no interior radicular com movimentos helicoidais (ALVES et al., 2005; BEER et al., 2012; LOPES et al., 2016).

Por outro lado, ao analisar a superfície dos blocos dentinários irradiados com laser diodo de alta potência (970nm), observou-se uma matriz orgânica 
amorfa e derretimento da dentina intertubular. Segundo JHINGAN et al. (2015), após irradiação com laser diodo 980nm (2W), a análise da superfície dentinária intrarradicular por meio de microscopia eletrônica de varredura, evidenciou o derretimento da camada de dentina tornando-a irregular como também observado por ALFREDO et al., 2009 e FARIA et al., 2013).

Estas alterações morfológicas observadas podem ser atribuídas ao efeito térmico provocado pelo superaquecimento e subsequente resfriamento da superfície quando o laser interage com o tecido dentinário (MARCHESAN et al., 2008b; ALFREDO et al., 2009; FARIA et al., 2011), fenômeno que explica o derretimento da dentina intertubular e superfície irregular pelo laser diodo 970nm.

Em relação à associação do laser $808 \mathrm{~nm}$ com solução de hipoclorito de sódio a 2,5\%, houve uma potencialização das alterações morfológicas da dentina causadas pelo laser comparado ao tratamento com laser sem imersão. Já ao associar o laser diodo 970nm com hipoclorito de sódio a 2,5\%, foi possível observar uma maior erosão da dentina intertubular comparado ao tratamento com laser 970nm sem imersão. Entretanto, ao associar clorexidina com demais lasers, observou-se uma menor alteração da estrutura dentinária.

WAGNER et al. (2016) obtiveram resultados semelhantes aos obtidos no presente estudo, ao avaliarem o efeito de diferentes protocolos de irrigação na estrutura da dentina radicular através de MEV e microscopia eletrônica de transmissão. A dentina intrarradicular apresentou alterações estruturais causadas pelo hipoclorito de sódio $2,5 \%$, enquanto que o tratamento com clorexidina, água destilada e solução salina preservaram a estrutura de colágeno, e se apresentaram incapaz de dissolver matéria orgânica. 
Dessa forma, ao avaliar a influência do laser de diferentes comprimentos de onda na superfície dentinária, o presente estudo concluiu que a aplicação do laser diodo 808nm e 970nm e hipoclorito de sódio a 2,5\% tiveram semelhança na descontaminação da superfície do bloco de dentina radicular, apesar de apresentarem alterações morfológicas na superfície dentinária. Entretanto, é válido ressaltar que apesar do efeito antimicrobiano semelhante, de acordo com estudos prévios na literatura (GARCEZ et al., 2015; ISOLA et al., 2017) o laser diodo pode apresentar a capacidade de estimular o reparo dos tecidos periapicais.

Entretanto, mais estudos devem ser realizados no sentido de buscar a efetividade do laser diodo em canais radiculares contaminados por biofilmes maduros, em condições mais próximas à realidade clínica, bem como a sua influência na morfologia da dentina no prognóstico do tratamento endodôntico. 



$$
\text { c. }
$$



Considerando os resultados obtidos, pode-se concluir que todos os protocolos terapêuticos foram capazes de reduzir o contingente bacteriano, sendo que o laser diodo $970 \mathrm{~nm}$ apresentou potencial antibacteriano semelhante ao do hipoclorito de sódio, e ao associar o laser diodo e soluções não houve melhora significativa na redução do contingente bacteriano. 

$\boldsymbol{R}_{\text {eferências }} \boldsymbol{B}_{\text {ibliográficas }}$ 

AFKHAMI, F.; POURHASHEMI, S.J.; SADEGH, M.; SALEHI, Y.; FARD, M.J. Antibiofilm efficacy of silver nanoparticles as a vehicle for calcium hydroxide medicament against Enterococcus faecalis. Journal of Dentistry, v.43, n.12, p.1573-9, 2015.

ALFREDO, E.; MARCHESAN M.A.; SOUSA-NETO M.D., BRUGNERA-JUNIOR A., SILVA-SOUSA Y.T.C. Temperature variation at the external root surface during $980-\mathrm{nm}$ diode laser irradiation in the root canal. Journal of Dentistry, v.36, n.7, p.529-3, 2008.

ALFREDO, E.; SOUZA-GABRIEL, A.E.; SILVA, S.R.; SOUSA-NETO, M.D.; BRUGNERA-JUNIOR, A.; SILVA-SOUSA, Y.T. Morphological alterations of radicular dentine pretreated with different irrigating solutions and irradiated with 980-nm diode laser. Microscopy Research and Technique, v.72, n.1, p.22-7, 2009.

AL-KARADAGHI, T.S.; FRANZEN, R.; JAWAD, H.A.; GUTKNECHT, N. Investigations of radicular dentin permeability and ultrastructural changes after irradiation with Er,Cr:YSGG laser and dual wavelength (2780 and $940 \mathrm{~nm}$ ) laser. Lasers in Medical Science, v.30, n.8, p.2115-21, 2015.

ALVES, D.R.; CUNHA, R.S.; DA SILVEIRA BUENO, C.E.; DE ALENCAR, A.H.; DE ARAÚJO ESTRELA, C.R.; DOS SANTOS, T.O.; ESTRELA, C. Antibacterial Potential of $2.5 \%$ Sodium Hypochlorite in Distinct Irrigation Protocols on Enterococcus faecalis Biofilm. The Journal of Contemporary Dental Practice, v.16, n.5, p:340-6. 2015.

ALVES, P.R.; ARANHA, N.; ALFREDO, E.; MARCHESAN, M.A.; BRUGNERA JUNIOR, A.; SOUSA-NETO, M.D. Evaluation of hollow fiberoptic tips for the conduction of Er:YAG laser. Photomedicine Laser Surgery, v.23, n.4, p.410-5, 2005.

ARNEIRO, R.A.; NAKANO, R.D.; ANTUNES, L.A.; FERREIRA, G.B.; FONTES, K. ANTUNES, L.S. Efficacy of antimicrobial photodynamic therapy for root canals infected with Enterococcus faecalis. Journal of Oral Science, v.56, n.4, p.277-85, 2014.

ASNAASHARI, M.; SAFAVI, N. Disinfection of Contaminated Canals by Different Laser Wavelengths, while Performing Root Canal Therapy. Lasers in Medical Science, v.4, n.1, p.8-16, 2013.

ASNAASHARI. M.; MOJAHEDI, S.M.; ASADI, Z.; AZARI-MARHABI, S.; MALEKI, A. A comparison of the antibacterial activity of the two methods of photodynamic therapy (using diode laser $810 \mathrm{~nm}$ and LED lamp $630 \mathrm{~nm}$ ) against Enterococcus faecalis in extracted human anterior teeth. Photodiagnosis and Photodynamic Therapy, v.13, p.233-7, 2016.

BAGO, I.; PLEČKO, V.; GABRIĆ PANDURIĆ, D.; SCHAUPERL, Z.; BARABA, A.; ANIĆ, I. Antimicrobial efficacy of a high-power diode laser, photo-activated disinfection, conventional and sonic activated irrigation during root canal treatment. International Endodontic Journal, v.46, n.4, p.339-47, 2013. 
BARATTO-FILHO, F.; DE CARVALHO, J.R. Jr.; FARINIUK, L.F.; SOUSANETO, M.D.; PÉCORA, J.D.; DA CRUZ-FILHO, A.M. Morphometric analysis of the effectiveness of different concentrations of sodium hypochlorite associated with rotary instrumentation for root canal cleaning. Brazilian Dental Journal, v.15, n.1, p.36-40, 2004.

BAZVAND, L.; AMINOZARBIAN, M,G.; FARHAD, A.; NOORMOHMMADI, H.; HASHEMINIA, S.M.; MOBASHERIZADEH, S. Antibacterial effect of triantibiotic mixture, chlorhexidine gel, and two natural materials Propalis and Aleo vera against Enterococcus feaecalis: An ex vivo study. Journal of Dental Research, v.11, p.469-74, 2014.

BEER, F.; BUCHMAIR, A.; WERNISCH, J.; GEORGOPOULOS, A.; MORITZ, A. Comparison of two diode lasers on bactericidity in root canals--an in vitro study. Lasers in Medical Science, v.27, n.2, p.361-4, 2012.

BEER, F.; FARMAKIS, E.T.; KOPIC, J.; KURZMANN, C.; MORITZ, A. Temperature Development on the External Root Surface During Laser-Assisted Endodontic Treatment applying a Microchopped Mode of a $980 \mathrm{~nm}$ Diode Laser. Photomed Laser Surgery. 2017. In press.

BOTTON, G.; PIRES, C.W.; CADONÁ, F.C.; MACHADO, A.K.; AZZOLIN, V.F.; CRUZ, I.B.; SAGRILLO, M.R.; PRAETZEL, J.R. Toxicity of irrigating solutions and pharmacological associations used in pulpectomy of primary teeth. International Endodontic Journal, v.49. n.8, p.746-54, 2016.

BRITTAN, J.L.; SPRAGUE, S.V.; MACDONALD, E.L.; LOVE, R.M.; JENKINSON, H.F.; WEST, N.X. In vivo model for microbial invasion of tooth root dentinal tubules. Journal of Applied Oral Science, v.24, n.2, p:126-35. 2016

BRUGNERA-JÚNIOR A.; ZANIN, F.; BARBIN, E.L.; SPANO, J.C., SANTANA, R.; PÉCORA, J.D. Effects of Er:YAG and Nd:YAG laser irradiation on radicular dentine permeability using different irrigating. Lasers in Surgery and Medicine, v.33, n.1, p.256-259, 2003.

CAMACHO-ALONSO, F.; SALMERÓN-LOZANO, P.; MARTÍNEZ-BENEYTO, Y. Effects of photodynamic therapy, $2 \%$ chlorhexidine, triantibiotic mixture, propolis and ozone on root canals experimentally infected with Enterococcus faecalis: an in vitro study. Odontology. 2016. In press.

CASTELO-BAZ, P.; MARTIN-BIEDMA, B.; RUIZ-PINON, M. Combined sodium hypochlorite and $940 \mathrm{~nm}$ diode laser treatment against mature $E$. faecalis biofilms in-vitro. Lasers in Medical Science, v.3, n.1, p.116-121, 2012.

DA COSTA RIBEIRO, A.; NOGUEIRA, G.E.; ANTONIAZZI, J.H.; MORITZ. A.; ZEZELL, D.M. Effects of diode laser $(810 \mathrm{~nm})$ irradiation on root canal walls: thermographic and morphological studies. Journal of Endodontics, v33, n.3, p.252-5, 2007. 
DAMETTO FR, FERRAZ CC, GOMES BP, ZAIA AA, TEIXEIRA FB, DE SOUZA-FILHO FJ. In vitro assessment of the immediate and prolonged antimicrobial action of chlorhexidine gel as an endodontic irrigant against Enterococcus faecalis. Oral Surgery, Oral Medicine, Oral Pathology, Oral Radiology, and Endodontology, v.99, n.6, p:768-72, 2005.

DE SOUZA, E.B.; CAI, S.; SIMIONATO, M.R.; LAGE-MARQUES, J.L. Highpower diode laser in the disinfection in depth of the root canal dentin. Oral Surgery, Oral Medicine, Oral Pathology, Oral Radiology, and Endodontology, v.106, n.1, p:68-72, 2008.

ESTEVES-OLIVEIRA, M., DE GUGLIELMI, C.A., RAMALHO, K.M.; ARANACHAVEZ, V.E.; EDUARDO, C.P. Comparison of dentin root canal permeability and morphology after irradiation with Nd:YAG, Er:YAG, and diode lasers. Lasers in Medical Science, v.25, p.5, p.755-60, 2010.

ESTRELA, C.; ESTRELA, C.R.; BARBIN, E.L.; SPANÓ, J.C.; MARCHESAN, M.A.; PÉCORA, J.D. Mechanism of action of sodium hypochlorite. Brazilian Dental Journal., v.13, n.2, p.113-7, 2002.

FARIA, M.I.; SOUSA-NETO, M.D.; SOUZA-GABRIEL, A.E.; ALFREDO, E.; ROMEO, U.; SILVA-SOUSA, Y.T. Effects of $980-\mathrm{nm}$ diode laser on the ultrastructure and fracture resistance of dentine. Lasers in Medical Science, v. 28, n.1, p.275-80, 2013.

FARIA, M.I.; SOUZA-GABRIEL, A.E.; ALFREDO, E.; MESSIAS, D.C.; SILVASOUSA, Y.T. Apical microleakage and SEM analysis of dentin surface after 980 $\mathrm{nm}$ diode laser irradiation. Brazilian Dental Journal; v.22, n.5, p.382-387, 2011.

FERNANDES, M.; DE ATAIDE, I. Nonsurgical management of periapical lesions. Journal of Conservative Dentistry v.13, n.4, p.240-5, 2010.

FLACH, N.; BÖTTCHER, D.E.; PAROLO, C.C.; FIRMINO, L.B.; MALT, M.; LAMMERS, M.L.; GRECCA, F.S. Confocal microscopy evaluation of the effect of irrigants on Enterococcusfaecalis biofilm: An in vitro study. Scanning, v.38, n.1, p:57-62. 2016.

GAD, F.; ZAHRA, T.; HASAN, T.; HAMBLIN, M.R. Effects of growth phase and extracellular slime on photodynamic inactivation of gram-positive pathogenic bacteria. Antimicrobial Agents and Chemotherapy, v.48, n.6, p.2173-8, 2004.

GARCEZ, A.S.; ARANTES-NETO, J.G.; SELLERA, D.P.; FREGNANI, E.R. Effects of antimicrobial photodynamic therapy and surgical endodontic treatment on the bacterial load reduction and periapical lesion healing. Three years follow up. Photodiagnosis and Photodynamic Therapy, v.12, n.4, p.575-80, 2015.

GEREK, M.; ASCI, S.; YAYLALI, D.I. Ex Vivo Evaluation of Antibacterial Effects of Nd:YAG and Diode Lasers in Root Canals. Biotechnology \& Biotechnological Equipment, v.24, n.3, p.2031-2034, 2010 
GOMES, B.P.; VIANNA, M.E.; ZAIA, A.A.; ALMEIDA, J.F.; SOUZA-FILHO, F.J.; FERRAZ, C.C. Chlorhexidine in endodontics. Brazilian Dental Journal., v.24, n.2, p.89-102, 2013.

GULSOY, M.; DERELI, Z.; TABAKOGLU, H.O.; BOZKULAK, O. Closure of skin incisions by980-nm diode laser welding. Lasers in Medical Science, v.21, n.1, p.5-10, 2006.

GUTKNECHT, N.; AL-KARADAGHI, T.S; AL-MALIKY, M.A.; CONRADS, G.; FRANZEN, R. The Bactericidal effect of 2780 and $940 \mathrm{~nm}$ Laser Irradiation on Enterococcus faecalis in Bovine Root Dentin Slices of Different Thicknesses. Photomedicine and Laser Surgery.; v.34, n.1, p.11-6, 2016.

GUTKNECHT, N.; FRANZEN, R.; SCHIPPERS, M.; LAMPERT, F. Bactericidal effect of a 980-nm diode laser in the root canal wall dentin of bovine teeth. Journal of Clinical Laser Medicine and Surgery, v.22, n.1, p.9-13, 2004.

GUTKNECHT, N.; VAN GOGSWAARDT, D.; CONRADS, G.; APEL, C.; SCHUBERT, C.; LAMPERT, F. Diode laser radiation and its bactericidal effect in root canal wall dentin. Journal of Clinical Laser Medicine and Surgery, v.18, n.2, p.57-60, 2000.

HAAPASALO, M. \& ORSTAVIK, D. In vitro infection and disinfection of dentinal tubules. Journal of Dental Research, v.66, n.8, p.1375-9, 1987.

HMUD, R.; KAHLER, W.A.; GEORGE, R.; WALSH, L.J. Cavitational effects in aqueous endodontic irrigants generated by nearinfrared lasers. Journal of Endodonticsv.36, n. 2, p.275-278, 2010.

ISOLA, G.; MATARESE, G.; LO GIUDICE, G.; BRIGUGLIO, F.; ALIBRANDI, A.; CRUPI, A.; CORDASCO, G.; RAMAGLIA, L. A New Approach for the Treatment of Lateral Periodontal Cysts withan 810-nm Diode Laser. The International Journal of Periodontics and Restorative Dentistry, v.37, n.1, p:120-129. 2017.

JHAJHARIA, K.; PAROLIA, A.; SHETTY, K.V.; MEHTA, L.K. Biofilm in endodontics: A review. Journal of International Society of Preventive and Community Dentistry, v.5, n.1, p.1-12, 2015.

JHINGAN, P.; SANDHU, M.; JINDAL, G.; GOEL, D.; SACHDEV, V. An in-vitro evaluation of the effect of $980 \mathrm{~nm}$ diode laser irradiation on intra-canal dentin surface and dentinal tubule openings after biomechanical preparation: Scanning electron microscopic study. Indian Journal of Dental Research, v.6, n.2, p.8590, 2015.

KANDASWAMY, D.; VENKATESHBABU, N.; GOGULNATH, D.; KINDO, A.J. Dentinal tubule disinfection with $2 \%$ chlorhexidine gel, propolis, morinda citrifolia juice, $2 \%$ povidone iodine, and calcium hydroxide. International Endodontic Journal., v.43, n.5, p.419-23, 2010.

KANUMURU, N.R.; SUBBAIAH, R. Bacterial Efficacy of $\mathrm{Ca}(\mathrm{OH})_{2}$ Against E.faecalis Compared with three Dental Lasers on Root Canal Dentin- An Invitro Study. Journal of Clinical and Diagnostic Research., v.8, n.1, p.11, 2014. 
KIRAN, S.; PRAKASH, S.; SIDDHARTH, P.R.; SAHA, S.; GEOJAN, N.E.; RAMACHANDRAN M. Comparative Evaluation of Smear Layer and Debris on the Canal Walls prepared with a Combination of Hand and Rotary ProTaper Technique using Scanning Electron Microscope. The Journal of Contemporary Dental Practice, v.17, n.7, p:574-81. 2016.

LEE, Y. RAN, S.H.; HONG, S.H.; LEE, J.K.; JI H.; KUM, K.Y. Antimicrobial efficacy of a polymeric chlorhexidine release device using in vitro model of Enterococcus faecalis dentinal tubule infection. Journal of Endodontics, v. 34, n.7, p. 855-8, 2008.

LEONI, G.B.; VERSIANI, M.A.; PÉCORA, J.D.; DAMIÃO DE SOUSA-NETO, M. Micro-computed tomographic analysis of the root canal morphology of mandibular incisors. Journal of Endodontics, v.40, n.5, p.710-6, 2014.

LIM, Z.; CHENG, J.L.; LIM, T.W. TEO, E.G.; WONG, J.; GEORGE, S.; KISHEN, A. Light activated disinfection: an alternative endodontic disinfection strategy. Australian Dental Journal, v.54, n.2, p.108-14, 2009.

LLENA, C.; FORNER, L.; CAMBRALLA, R.; LOZANO, A. Effect of three different irrigation solutions applied by passive ultrasonic irrigation. Restorative Dentistry \& Endodontics, v.40, n.2, p.143-8, 2015.

LO GIUDICE, G.; CUTRONEO, G.; CENTOFANTI, A.; ARTEMISIA, A.; BRAMANTI, E.; MILITI, A.; RIZZO, G.; FAVALORO, A.; IRRERA, A.; LO GIUDICE, R.; CICCIÙ, M. Dentin morphology of root canal surface: $A$ quantitative Evaluation Based on a Scanning Electronic Microscopy Study. Biomedical Research International. 2015. In press.

LOPES, F.; ROPERTO, R.; AKKUS, A.; AKKUS, O.; SOUZA-GABRIEL, A.; SOUSA-NETO, M. Effects of different lasers on organic/inorganic ratio of radicular dentin. Lasers in Medical Science, v.31, n.3, p.415-420, 2016.

LÓPEZ-JIMÉNEZ, L.; ARNABAT-DOMÍNGUEZ, J.; VIÑAS, M.; VINUESA, T. Atomic force microscopy visualization of injuries in Enterococcus faecalis surface caused by Er,Cr:YSGG and diode lasers. Medicina Oral, Patología Oral y Cirugía Bucal, v.20, n.1, p.45-51, 2015.

MAENOSONO, R.M.; BIM JÚNIOR, O.; DUARTE, M.A.H.; PALMA-DIBB, R.G.; WANG, L.; ISHIKIRIAMA, S.K. Diode laser irradiation increases microtensile bond strength of dentin. Brazilian Oral Research, v. 29, n.1, p. 01-05, 2015.

MARCHESAN, M.A.; BRUGNERA-JUNIOR, A.; SOUZA-GABRIEL, A.E.; CORREASILVA,S.R.; SOUSANETO,M.Ultrastructural analysis of root can al dentine irradiated with $980 \mathrm{~nm}$ diode laser energy at diferente parameters. Photomedicine Laser in Surgery, v.26, n.3, p.235-40, 2008.

MASHALKAR, S.; PAWAR, M.G.; KOLHE, S.; JAIN, D.T. Comparative evaluation of root canal disinfection by conventional method and laser: an in vivo study. Nigerian Journal of Clinical Practice, v.17, n.1, p.67-74, 2014. 
MEHRVARZFAR, P.; SAGHIRI, M.A.; ASATOURIAN, A.; FEKRAZAD, R.; KARAMIFAR, K.; ESLAMI, G.; DADRESANFAR, B. Additive effect of a diode laser on the antibacterial activity of $2.5 \% \mathrm{NaOCl}, 2 \% \mathrm{CHX}$ and MTAD against Enterococcus faecalis contaminating rootcanals: an in vitro study. Journal of Oral Science, v.53, n.3, p.355-60, 2011.

MISURIYA, A.; BHARDWAJ, A.; BHARDWAJ, A.; AGGRAWAL, S.; KUMAR, P.P.; GAJJAREPU, S. A comparative antimicrobial analysis of various root canal irrigating solutions on endodontic pathogens: an in vitro study. Journal of contemporary dental practice, v.15, n.2, p.153-60, 2014.

MOHAMMADI, Z.; GIARDINO, L.; PALAZZI, F.; ASGARY, S. Agonistic and antagonistic interactions between chlorhexidine and other endodontic agents: $A$ critical review. Iranian Endodontic Journal., v.10, n.1, p.1-5, 2015.

MORAGO, A; ORDINOLA-ZAPATA, R; FERRER-LUQUE, C.M.; BACA, P.; RUIZ-LINARES, M.; ARIAS-MOLIZ, M.T. Influence of Smear Layer on the Antimicrobial Activity of a Sodium Hypochlorite/Etidronic Acid Irrigating Solution in Infected Dentin. Journal of Endodontics, 2016. In press.

MORITZ, A.; GUTKNECHT, N.; SCHOOP, U.; GOHARKHAY, K.; DOERTBUDAK, O.; SPERR, W. Irradiation of infected root canals with a diode laser in vivo: results of microbiological examinations. Lasers Surgery Medicine, v.21, n.3, p.221-6, 1997.

MUHAMMAD, O.H.; ROCCA J.P.; FORNAIN,I C.; MEDIONI, E. Evolution of the role of phototherapy during endodontic decontamination. Laser Therapy, v.24, n.4, p 291-302, 2015.

PLADISAI, P.; AMPORNARAMVETH, R.S.; CHIVATXARANUKUL, $P$. Effectiveness of Different Disinfection Protocols on the Reduction of Bacteria in Enterococcus faecalis Biofilm in Teeth with Large Root Canals. Journal of Endodontics, v.43, n.3, p: 460-4, 2016.

PORTENIER, I.; TUOMOS, M.T.; WALTIMO, M.; HAAPASALO, MP. Enterococcus Faecalis - The root canal survivor and 'star' in post-treatment disease. Endodontics Topics, v.6, p.135-59, 2003.

PREETHEE, T.; KANDASWAMY, D.; ARATHI, G.; HANNAH, R. Bactericidal effect of the $908 \mathrm{~nm}$ diode laser on Enterococcus faecalis in infected root canals. Journal of Conservative Dentistry, v.15, n.1, p:46-50. 2012.

PRICE, R.B.; FERRACANE, J.L.; SHORTALL, A.C. Light-Curing Units: A Review of What We Need to Know. Journal of Dental Research, v.94, n.9, p.1179-86, 2015.

RAN, S.; GU S.; WANG J.; ZHU C.; LIANG. Dentin tubule invasion by Enterococcus faecalis under stress conditions ex vivo. European Journal of Oral Sciences., v.123, p: 362-368, 2015.

REDDY, J.M.; LATHA, P.; GOWDA, B.; MANVIKAR, V.; VIJAYALAXMI, D.B.; PONANGI, K.C. Smear layer and debris removal using manual ni-ti files 
compared with rotary protaper $\mathrm{Ni}$ - Ti files - an in-vitro sem study. Journal of International Oral Health., v.6, n.1, p.89-94, 2014.

RIBEIRO, R.G.; MARCHESAN, M.A.; SILVA, R.G.; SOUSA-NETO, M.D.; PÉCORA, J.D. Dentin permeability of the apical third in different groups of teeth. Brazilian Dental Journal, v.21, n.3, p.216-9, 2010.

RÔÇAS, I.N.; PROVENZANO, J.C.; NEVES, M.A.; SIQUEIRA, J.F. JR. Disinfecting Effects of Rotary Instrumentation with Either 2.5\% Sodium Hypochlorite or $2 \%$ Chlorhexidine as the Main Irrigant: A Randomized Clinical Study. Journal of Endodontics, v.42, n.6, p:943-7, 2016.

ROMEO, U.; SANDHU, M.; JINDAL, G.; GOEL, D.; SACHDEY, V. An in-vitro evaluation of the effect of $980 \mathrm{~nm}$ diode laser irradiation on intra-canal dentin surface and dentinal tubule openings after biomechanical preparation: Scanning electron microscopic study. Indian Journal Dentistry, v.6, p. 85-90, 2015.

SAHA, S.; NAIR, R.; ASRAN, I.H. Comparative evaluation of Propolis, metronidazole with chlorhexidine, calcium hydroxide and Curcuma longa extract as intracanal medicament against $E$. faecalis - An in vitro study. Journal of Clinical and Diagnostic Research, v.9, n.11, p.19-21, 2015.

SCHOOP, L.; KLUGER, W .; DERVISBEGOVIC, $S$.; GOHARKHAY, $\mathrm{K}$.; WERNISCH, J .; GEORGOPOULOS, A .; SPERR W .; MORITZ, A. Innovative wavelengths in endodontic treatment. Lasers in Surgery and Medicine, v. 38, n.6, p. 624-30, 2006.

SCHOOP, U.; GOHARKHAKY, K.; KLIMSHA J.; ZAGLER, M.; WERNICH, J.; GEORGOPOULOS, A. The use of Er, Cr, YSGG laser in endodontic treatment. The Journal of the American Dental Association, v.138, p.949-955, 2007.

SIQUEIRA, J.F. JR.; RÔÇAS, I.N.; PAIVA, S.S.; GUIMARÃES-PINTO, T.; MAGALHÃES, K.M.; LIMA, K.C. Bacteriologic investigation of the effects of sodium hypochlorite andchlorhexidine during the endodontic treatment of teeth with apical periodontitis. Oral Surgery, Oral Medicine, Oral Pathology, Oral Radiology, and Endodontology, v.104, n.1, p:122-30, 2007.

SIQUEIRA, J.F.; RÔÇAS, I.N.; RICUCCI, D. Biofilms in endodontic infection. Endodontics Topics, v.22, n.12, p.33-49, 2012

SOHRABI, K.; SOORATGAR, A.; ZOLFAGHARNASAB, K.; KHARAZIFARD, M.J.; AFKHAMI, F. Antibacterial Activity of Diode Laser and Sodium Hypochlorite in Enterococcus Faecalis-Contaminated Root Canals. Iranian Endodontic Journal, v.11, n.1, p:8-12, 2016.

STUART, C.H.; SCHWARTZ, S.A.; BEESON, T.J.; OWATZ, CB. Enterococcus faecalis: its role in rootcanal treatment failure and current concepts in retreatment. Journal of Endodontics, v.32, n.2, p.93-8. 2006.

TOSUN, S.; CULHA, E.; AYDIN, U.; OZSEVIK, A.S. The combined occluding effect of sodium fluoride varnish and $\mathrm{Nd}$ :YAG laser irradiation on dentinal tubules-A CLSM and SEM study. Scanning, 2016. In press. 
UZUN, I.; KESKIN, C.; ÖZSU, D.; GÜLER, B.; AYDEMIR H. Push-out bond strength of oval versus circular fiber posts irradiated by erbium-doped yttrium aluminum garnet laser. Journal of Prosthetic Dentistry, v.16, p.107-4, 2016.

VALERA, M.C.; OLIVEIRA, S.A.; MAEKAWA, L.E.; CARDOSO, F.G.; CHUNG, A.; SILVA, S.F.; CARVALHO, C.A. Action of Chlorhexidine, Zingiber officinale, and Calcium Hydroxide on Candida albicans, Enterococcus faecalis, Escherichia coli, and Endotoxin in the Root Canals. The Journal of Contemporary Dental Practice, v.17, n.2, p.114-8, 2016.

VATKAR, N.A.; HEGDE, V.; SATHE, S. Vitality of Enterococcus faecalis inside dentinal tubules after five root canal disinfection methods. Journal of Conservative Dentistry., v.19, n.5, p.445-9, 2016.

VERSIANI, M.A.; ORDINOLA-ZAPATA, R.; KELEŞ A.; ALCIN, H.; BRAMANTE, C.M.; PÉCORA, J.D.; SOUSA-NETO, M.D. Middle mesial canals in mandibular first molars: A micro-CT study in different populations. Archives of Oral Biology, v.61, n.1, p.130-7, 2016.

VIANNA, M.E.; HORZ, H.P.; GOMES, B.P.F.A.; CONRADS, G. In vivo evaluation of microbial reduction after chemo-mechanical preparation of human root canals containing necrotic pulp tissue. International Endodontic Journal, v.39, n.6, p.484-92, 2006.

VIOLICH, D. R.; CHANDLER, N. P. The smear layer in endodontics - a review. Internacional Endodontic Journal, v. 43, n. 1, p. 2-15, 2010.

WAGNER, M.H.; DA ROSA, R.A.; DE FIGUEIREDO, J.A.; DUARTE, M.A.; PEREIRA, J.R.; SÓ, M.V. Final irrigation protocols may affect intraradicular dentin ultrastructure. Clinical Oral Investigations. 2016. In press.

WONG D.T.; CHEUNG G.S. Extension of bactericidal effect of sodium hypochlorite into dentinal tubules. Journal of Endodontics, v.40, p.825-9, 2014.

YEH, S.; JAIN, K.; ANDREANA, S. Using a diode laser to uncover dental implants in second-stage surgery. European Journal of General Dentistry, v. 53 , n.6, p.414-7, 2005.

ZANDI, H.; RODRIGUES, R.C.; KRISTOFFERSEN, A.K.; ENERSEN, M.; MDALA, I.; ØRSTAVIK, D.; RÔÇAS, I.N.; SIQUEIRA, J.F. JR. Antibacterial Effectiveness of 2 Root Canal Irrigants in Root-filled Teeth with Infection: A Randomized Clinical Trial. Journal of Endodontic, v.42, n.9, p:1307-13, 2016.

ZOU, L.; SHEN Y.; LI, W.; HAAPASALO, M. Penetration of sodium hypochlorite into dentin. Journal of Endodontics, v.36, n.5, p.793-6. 2010. 